\title{
Injury-Dependent Müller Glia and Ganglion Cell Reprogramming during Tissue Regeneration Requires Apobec2a and Apobec2b
}

\author{
Curtis Powell, Fairouz Elsaeidi, and Daniel Goldman \\ The Molecular and Behavioral Neuroscience Institute and Department of Biological Chemistry, University of Michigan, Ann Arbor Michigan 48109
}

Unlike mammals, adult zebrafish are able to regenerate multiple tissues including those of the CNS. In the zebrafish retina, injury stimulates Müller glia dedifferentiation into a multipotent retinal progenitor that is capable of regenerating all lost cell types. This dedifferentiation is driven by the reactivation of gene expression programs that share many characteristics with those that operate during early development. Although the mechanisms underlying the reactivation of these programs remain unknown, it is likely that changes in DNA methylation play a significant role. To begin investigating whether DNA demethylation may contribute to retina regeneration, we characterized the expression of genes associated with DNA demethylation in the uninjured and injured retina. We found that two cytidine deaminases (apobec $2 a$ and apobec $2 b$ ) were expressed basally in the uninjured retina and that they were induced in proliferating, dedifferentiated Müller glia. The maximal induction of $a p o b e c 2 b$ required Asclla, but was independent of Lin28, and therefore defines an independent signaling pathway stemming from Ascl1a. Strikingly, when Apobec2a or Apobec2b was knocked down by antisense morpholino oligonucleotides, the proliferative response of Müller glia following injury was significantly reduced and injury-dependent induction of asclla and its target genes were inhibited, suggesting the presence of a regulatory feedback loop between Apobec proteins and ascl1a. Finally, Asclla, Apobec2a and Apobec2b were found to be essential for optic nerve regeneration. These data identify an essential role for Apobec proteins during retina and optic nerve regeneration and suggest DNA demethylation may underlie the reprogramming of cells to mount a regenerative response.

\section{Introduction}

While all the cells of an organism are genetically equivalent, each has its own unique identity. Part of this identity is established by epigenetic marks such as 5-methylcytosine (5mC). DNA methylation predominantly occurs at $\mathrm{CpG}$ dinucleotides, and its presence in promoter regions is highly correlated with the repression of gene transcription (Herman and Baylin, 2003). DNA demethylation is an early event in reprogramming somatic cells to a pluripotent state as seen in nuclear transfer studies (Simonsson and Gurdon, 2004; Jullien et al., 2011), heterokaryon formation (Bhutani et al., 2010) and induced pluripotent stem cell generation (Mikkelsen et al., 2008).

During zebrafish retina regeneration, Müller glia undergo multiple shifts in identity as they dedifferentiate, proliferate, and finally differentiate to regenerate new neurons and glia (Fausett and Goldman, 2006; Raymond et al., 2006; Bernardos et al., 2007; Fimbel et al., 2007; Fausett et al., 2008; Ramachandran et al.,

\footnotetext{
Received Nov. 7, 2011; revised Dec. 2, 2011; accepted Dec. 8, 2011.

Author contributions: C.P. and D.G. designed research; C.P. and F.E. performed research; C.P. and D.G. analyzed data; C.P. and D.G. wrote the paper.

This work was supported by NEI Grant R01 EY018132 (D.G.) and the University of Michigan Genetics Training Grant 5T32GM007544-33 (C.P.). We thank Dr. David Jones for generously providing us with clones of zebrafish apobec $2 a$ and $a p o b e c 2 b$ and antibodies against zebrafish Apobec2a and Apobec2b. We also thank the Goldman laboratory for helpful comments on this work.

Correspondence should be addressed to Daniel Goldman at the above address. E-mail: neuroman@umich.edu. DOI:10.1523/JNEUROSCI.5603-11.2012

Copyright $\odot 2012$ the authors $\quad 0270-6474 / 12 / 321096-14 \$ 15.00 / 0$
}

2010a,b). These cell transitions are associated with the activation and inhibition of specific gene regulatory programs. Although the mechanisms underlying these programming changes are largely unknown, we hypothesize that one such mechanism is the active modification of the DNA methylation landscape.

While the events of DNA methylation are well characterized, those of DNA demethylation remain unresolved. Developmental DNA demethylation in zebrafish is thought to occur through the coupling of an Apobec cytidine deaminase, a glycosylase, and a Gadd45 protein (Rai et al., 2008). In this mechanism $5 \mathrm{mC}$ is converted to a thymidine through deamination by an Apobec protein. More recently it was proposed that $5 \mathrm{mC}$ is first converted to 5 -hydroxymethylcytosine ( $5 \mathrm{hmC}$ ) by TET proteins (Ito et al., 2010; Mohr et al., 2011), which can then be deaminated by Apobec proteins (Guo et al., 2011; He et al., 2011). Next, MBD4 and TDG (thymine-DNA glycosylase) DNA glycosylases remove the modified base (Zhu et al., 2000, 2009; He et al., 2011), and base excision repair processes replace the abasic site with an unmethylated cytosine. Although a number of studies have suggested roles for these proteins in DNA demethylation (Morgan et al., 2004; Ma et al., 2009a,b; Bhutani et al., 2010; Popp et al., 2010; Wu and Zhang, 2010; Cortellino et al., 2011; Guo et al., 2011), none have investigated whether these proteins contribute to gene expression changes during Müller glia dedifferentiation and zebrafish retina regeneration.

In this study, we begin to characterize the potential role of DNA demethylation during zebrafish retina regeneration by an- 
Table 1. List of primers and applications

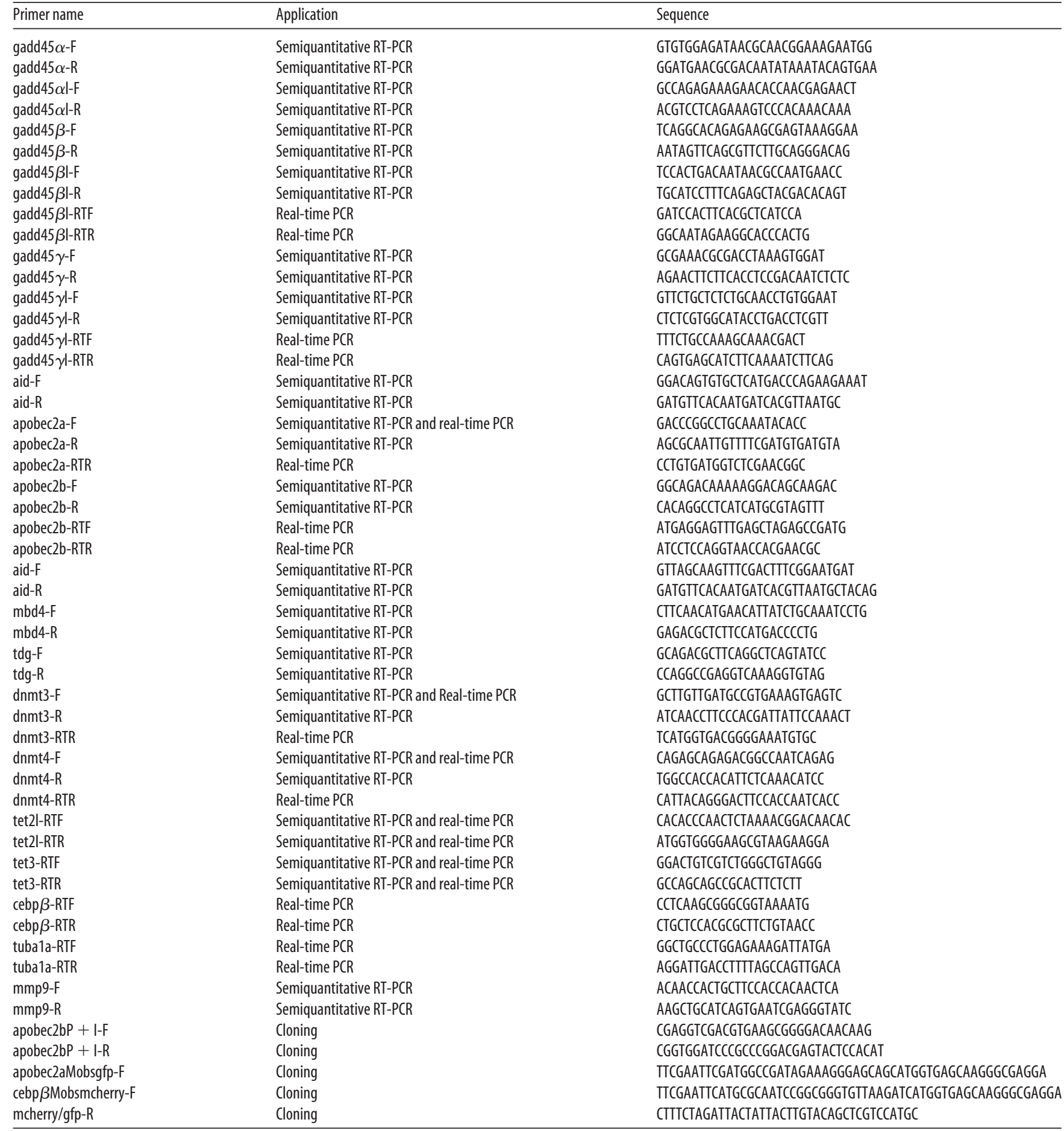

$F$, Forward; $R$, reverse.

alyzing injury-dependent transcriptional regulation of genes correlated with DNA demethylation. We show that during retina regeneration the expression of apobec $2 a$ and $a$ pobec $2 b$ is induced in dedifferentiating Müller glia and that during optic nerve regeneration $a p o b e c 2 b$ is induced in retinal ganglion cells. Importantly, we found that retina and optic nerve regeneration were significantly attenuated following knockdown of Apobec2a and Apobec 2 b. Finally, we provide evidence for signaling components upstream and downstream of these Apobec proteins during regeneration.

\section{Materials and Methods}

Animals. Zebrafish were kept at $26-28^{\circ} \mathrm{C}$ on a $14 / 10 \mathrm{~h}$ light/dark cycle. Fish of either sex were used in all experiments. Transgenic 1016 tubala: $g f p$ fish were previously described (Fausett and Goldman, 2006). The apobec $2 b P+I: g f p$ expression vector contains $1.85 \mathrm{~kb}$ of $5^{\prime}$ flanking apobec $2 b$ DNA, exon 1, intron 1, and $63 \mathrm{bp}$ of exon 2 ( $8.934 \mathrm{~kb}$ total; see Fig. $3 A$ ) that was amplified from zebrafish DNA with Phusion DNA Polymerase (New England Biolabs) using apobec2bP+I-F and apobec $2 \mathrm{bP}+\mathrm{I}-\mathrm{R}$ primers that harbor a Sall and a BamH1 site at their $5^{\prime}$ ends, respectively (Table 1 ). This PCR fragment was cloned within the 
pT2AL200R150G Tol2 vector (Urasaki et al., 2006) in frame to the $g f p$ sequence followed by an SV40 polyA signal sequence. The construct was injected into single-cell zebrafish embryos, which were raised to adulthood and screened for transgenic progeny. Five independent lines were selected and grown to adulthood, each exhibiting a similar phenotype.

RNA isolation and PCR. Total RNA was isolated using TRIzol reagent (Invitrogen) and treated with DNase (Invitrogen). cDNA synthesis was performed using $1 \mu \mathrm{g}$ of purified RNA, $500 \mathrm{ng}$ of random hexamer primers (Invitrogen) and M-MuLV Reverse Transcriptase (New England Biolabs). PCRs were done using TaqDNA polymerase and gene-specific primers (Table 1). The gadd $45 \beta$, gadd $45 \gamma, \mathrm{mbd4}$, and $t d g$ real-time specific primers were designed using previously validated sequences (Rai et al., 2008) and the asclla, lin28, pax6a, pax6b, gapdh, 124 (ribosomal protein L24), and $\beta$-actin primers have been described previously (Ramachandran et al., 2010b; Veldman et al., 2010). Real-time PCRs were performed in triplicate with SYBR green fluorescein on an iCycler realtime PCR detection system (Bio-Rad).

Retina injury, optic nerve lesions, and morpholino-mediated gene knockdown. Fish were anesthetized in $0.02 \%$ tricaine methane sulfonate before retina and optic nerve surgeries. Eye lesions were performed as described previously (Ramachandran et al., 2010b). Briefly, while anesthetized, fish were placed under a dissecting microscope for visualization and the right eye was gently rotated in its socket and stabbed through the sclera with a 30 gauge needle eight times (twice in each quadrant) when total RNA was isolated for reverse transcriptase (RT)-PCR, six times when RNA was isolated after morpholino injection and electroporation (three times in each hemisphere), and four times ( 1 time in each quadrant) for immunoflourescence and in situ hybridization.

To deliver morpholinos to the injured retina, a 30 gauge needle was attached to a Hamilton syringe and $\sim 0.7 \mu \mathrm{l}$ was injected into the vitreous at the time of injury. The untagged Control, $3^{\prime}$-lissamine-tagged Control, asclla and $\operatorname{lin} 28$ morpholinos have been described previously (Fausett et al., 2008; Ramachandran et al., 2010b; Veldman et al., 2010). The 3'lissamine-tagged apobec $2 a$ and apobec $2 b$ and the $3^{\prime}$-carboxyfluorescein $c e b p \beta$ morpholinos (Gene Tools, LLC) were designed using previously validated target sequences (Rai et al., 2008, 2010). Morpholino delivery to cells was facilitated by electroporation as previously described (Ramachandran et al., 2010b). For immunohistochemical studies on morpholino-injected samples, eyes were harvested $4 \mathrm{~d}$ postinjury (dpi) to analyze the effect of the morpholino on Müller glia proliferation. When RNA was collected for expression studies of morpholino-injected samples, retinas were isolated 2 dpi to negate any transcriptional difference occurring solely due to potential differences in Müller glia proliferation. We previously showed that Müller glia proliferation begins at $\sim 2 \mathrm{dpi}$ and is at its maxima at 4 dpi (Fausett et al., 2008).

Optic nerve lesion and retinal explants were performed as described previously (Veldman et al., 2010). Briefly, explants were performed $4 \mathrm{~d}$ after optic nerve transection and morpholino treatment. Retinas were isolated and cut into $0.5 \mathrm{~mm}$ squares with a razor blade and digested with hyaluronidase $(1 \mathrm{mg} / \mathrm{ml})$ for $15 \mathrm{~min}$ at room temperature. Explants were rinsed three times with L15 culture media and plated, one retina per plate that was precoated with poly-L-lysine and laminin. Explants were cultured in $0.5 \mathrm{ml}$ of L15 media containing $8 \%$ fetal calf serum, $3 \%$ zebrafish embryo extract and antibiotic/antimycotic at $28^{\circ} \mathrm{C}$ for $4 \mathrm{~d}$ in a humidified ambient air incubator. Adherent explants were quantified for neurite length and density as previously described (Veldman et al., 2010). Morpholino-mediated knockdown in adult retinal ganglion cells following optic nerve transection was accomplished by placing a small piece of Gelfoam, soaked in morpholino ( $1 \mu \mathrm{l}$ of a $1 \mathrm{~mm}$ morpholino) onto the lesioned optic nerve stump for $1 \mathrm{~d}$ and subsequently removed.

Morpholino validation constructs and Western blots. To validate the functionality of the antisense morpholinos introduced in our study, constructs were created that included the binding sequence of each morpholino preceding the sequence of $m$ Cherry or $g f p$. The apobec $2 a$ morpholino binding site was cloned into the pcs $2 \mathrm{p}+$ vector preceding the sequence of $g f p$ using the $g f p$ sequence as template and the apobec2aMobsgfp-F and the mcherry/gfp-R primers (Table 1 ) and the restriction enzymes EcoR1 and Xba1 [pcs2p + apobec $2 a$ Mo (morpholino) bs-gfp]. The cebp $\beta$ morpholino binding site was cloned into the pcs $2 p+$ vector preceding the sequence of $m$ Cherry using the $m$ Cherry sequence as template and the cebp $\beta$ Mobsmcherry-F and the mcherry/gfp-R primers (Table 1 ) and the restriction enzymes EcoR1 and Xbal (pcs $2 \mathrm{p}+\operatorname{cebp} \beta$ Mo bs-mCherry). The ptal apo $2 b P+I: g f p$ vector which includes the binding site for the $a p o b e c 2 b$ morpholino was used for the validation of the apobec $2 b$ morpholino. Purified constructs were microinjected into single cell embryos at a concentration of $2 \mathrm{ng} / \mu \mathrm{l}$ in conjunction with $0.125 \mathrm{~mm}$ lissaminetagged (apobec $2 a$ and apobec $2 b)$ or fluorescein-tagged (cebp $\beta$ ) experimental morpholino or $0.125 \mathrm{~mm}$ lissamine-tagged or untagged Control morpholino. Microinjections were analyzed for mCherry and GFP expression $1 \mathrm{~d}$ postfertilization. Experimental morpholino injections demonstrated a complete block of GFP (apobec $2 a$ and $a p o b e c 2 b$ morpholinos) or mCherry (cebp $\beta$ morpholino) while control morpholinos showed no effect.

To determine the efficiency of morpholino knockdown in the injured retina, Western blots were performed on protein isolated from retinas harvested $4 \mathrm{~d}$ after intraocular injection and electroporation of $0.25 \mathrm{~mm}$ morpholino. Six injections were performed to each eye. Retinas were harvested into nuclei lysis buffer (50 mм Tris- $\mathrm{HCl}, \mathrm{pH} 7.5,10 \mathrm{~mm}$ EDTA, $1 \%$ SDS) including Protease Inhibitor Cocktail (Thermo Scientific) and sonicated on ice. Protein concentrations were measured using the BCA assay (Pierce), and $40 \mu \mathrm{g}$ of protein was run for each sample on a $10 \%$ polyacrylamide gel. Rabbit anti-Apobec $2 \mathrm{a}$ and anti-Apobec $2 \mathrm{~b}$ antibodies were provided by David Jones (University of Utah, Salt Lake City, Utah) (Rai et al., 2008) and were used at a dilution of 1:2000. After probing for the deaminases, the blots were stripped for $30 \mathrm{~min}$ at $70^{\circ} \mathrm{C}(50 \mathrm{~mm}$ Tris$\mathrm{HCl}, \mathrm{pH} 7.5,2 \% \mathrm{SDS}, 50 \mathrm{~mm}$ DTT) and reprobed for glutamine synthetase (GS) as a loading control (1:2000, Millipore Bioscience Research Reagents). Anti-rabbit and anti-mouse HRP secondary antibodies and chemiluminescence (Roche) were used for protein detection. Western blots were quantified by densitometry using ImageJ software. Protein levels were normalization to GS expression.

$B r d U$, wedelolactone, and ethyl pyruvate injections. To identify dividing cells, fish were injected intraperitoneally with $15 \mu \mathrm{l}$ of $20 \mathrm{~mm}$ BrdU stock $3.5 \mathrm{~h}$ before harvesting at $4 \mathrm{dpi}$. Eyes were sectioned and assayed for BrdU immunofluorescence.

Wedelolactone (Calbiochem) and ethyl pyruvate (Sigma-Aldrich), inhibitors of NF- $\kappa$ B signaling (Daroczi et al., 2009), were injected intravitreously into the eye at the time of injury at concentrations of $2 \mu \mathrm{M}$ and $25 \mathrm{~mm}$ stock respectively using a 30 gauge needle attached to a Hamilton syringe. Six injections of $1 \mu \mathrm{l}$ of drug were performed for each eye analyzed, followed by retina harvest at 2 dpi. Gene expression analysis was then performed on retina RNA and compared with control vehicle injections (20\% DMSO).

Tissue preparation. Fish were given an overdose of tricaine methane sulfonate, and the eyes from adult fish were enucleated, followed by the removal of the lens and immersion into fresh $4 \%$ paraformaldehyde in $0.1 \mathrm{~m}$ phosphate buffer, $\mathrm{pH} 7.4$, for $4 \mathrm{~h}$ at room temperature or overnight at $4^{\circ} \mathrm{C}$. After fixation, tissues were cryoprotected in phosphate-buffered $20 \%$ sucrose for $6-12 \mathrm{~h}$ before embedding with Tissue-Tek O.C.T. compound (Sakura Finetek). Embedded samples were kept frozen at $-80^{\circ} \mathrm{C}$ until sectioned to $10 \mu \mathrm{m}$ on a CM3050S cryostat (Leica). Sections were collected on Superfrost/Plus slides (Fisher Scientific), dried and stored at $-80^{\circ} \mathrm{C}$.

Immunofluorescence. Immunofluorescence was performed as described previously (Ramachandran et al., 2010b) using the following primary antibodies: rat anti-BrdU (dividing cell marker, 1:400, Abcam), mouse anti-PCNA (proliferating cell nuclear antigen; dividing cell marker, 1:500, Sigma), rabbit anti-GFP (1:1000, Invitrogen), rabbit anticleaved caspase-3 (cell death marker, 1:50, Cell Signaling Technology) and mouse anti-GS (Müller glia marker, 1:500, Millipore Bioscience Research Reagents). Secondary anti-mouse, anti-rabbit, or anti-rat antibodies were conjugated to Alexa Fluor 488 (1:1000, Invitrogen) or cyanine 3 (1:250, Jackson ImmunoResearch). Antigen retrieval for BrdU and PCNA staining was performed by either boiling the sections in 10 mM sodium citrate and $0.05 \%$ Tween 20 for 20 min and cooling for another 20 min or by pretreating the sections with $2 \mathrm{~N} \mathrm{HCl} \mathrm{for} 22 \mathrm{~min}$ at $37^{\circ} \mathrm{C}$ followed by two $5 \mathrm{~min}$ washes with $100 \mathrm{~mm}$ sodium borate. Blocking was performed for $1 \mathrm{~h}$ with $3 \%$ donkey serum (Invitrogen) in PBS- 
A
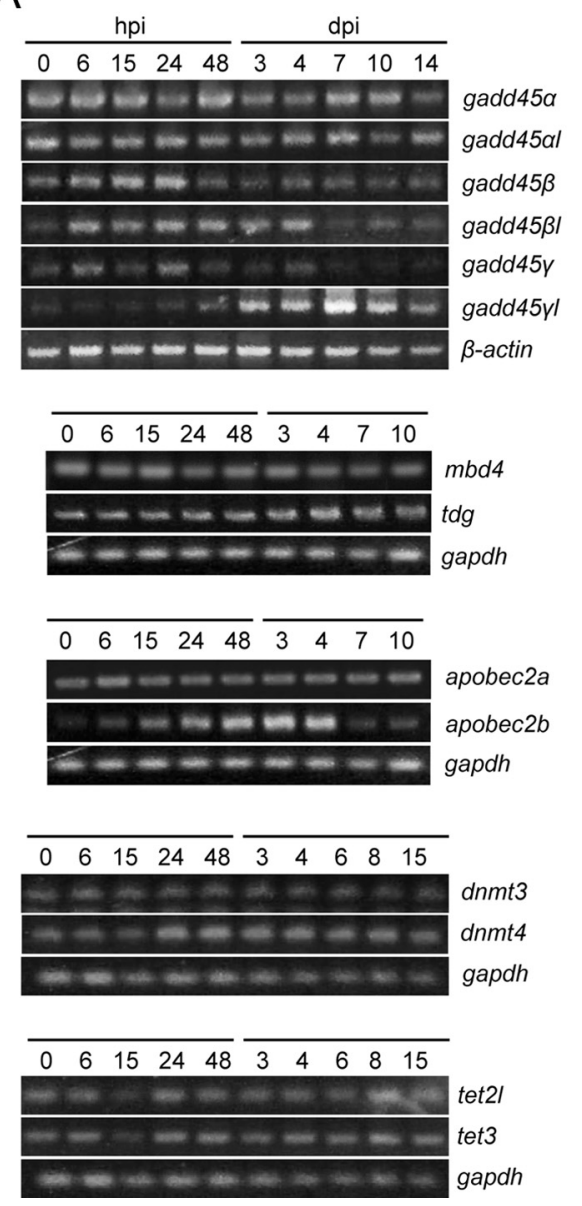

B
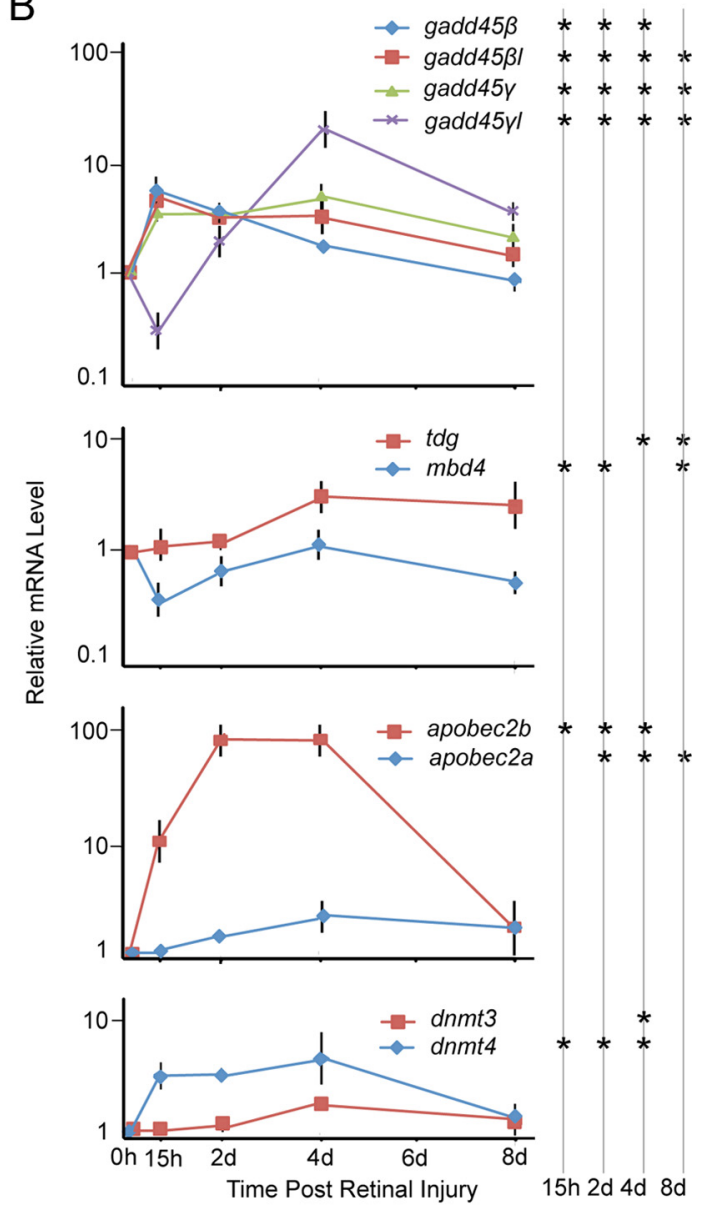

Figure 1. Injury-dependent regulation of genes correlated with DNA demethylation. A, RT-PCR analysis of indicated mRNAs isolated from retina at various times postinjury by poke with a 30 gauge needle. The expression of $\beta$-actin and gapdh served as the internal controls. One representative of three independent time courses is shown. $\boldsymbol{B}$, Real-time PCR quantification of indicated mRNAs isolated from retina at various times postinjury (labeled on the bottom $x$-axis). $y$-axis is fold induction in $\log s c a l e$ and is normalized to $0 \mathrm{~h}(0 \mathrm{~h}$ ), i.e., the uninjured retina, which was assigned a value of 1 . The expression of gapdh served as the internal control. Data represent means \pm SD ( $n=3$ individual cDNA sets; compared with control, time points marked with an asterisk have a $p<0.05$ ).

$0.1 \%$ Tween. Following immunofluorescent staining, slides were rinsed with water and allowed to dry in the dark before coverslipping with $2.5 \%$ polyvinyl alcohol/1,4-diazabicyclo-[2.2.2] octane.

In situ hybridization. In situ hybridizations were performed with antisense digoxigenin (DIG)-labeled RNA probes as described previously (Ramachandran et al., 2010b). Sense control probes were generated and showed no signal above background (data not shown). Clones of apobec $2 a$ and $a p o b e c 2 b$ were kindly provided by Dr. David Jones (University of Utah, Salt Lake City, Utah) (Rai et al., 2008). Full-length antisense DIG-labeled probes were created using restriction endonuclease linearized plasmid, SP6 RNA polymerase (Promega), and DIG rNTPs (Roche) as described previously (Fausett and Goldman, 2006).

TUNEL assay. TUNEL was performed on $10 \mu \mathrm{m}$ retina sections harvested 2 and $4 \mathrm{~d}$ after intraocular injection and electroporation of 0.25 $\mathrm{mm}$ morpholino. After digestion for $20 \mathrm{~min}$ with Proteinase K (Roche) at $37^{\circ} \mathrm{C}(10 \mu \mathrm{g} / \mathrm{ml}$ Proteinase $\mathrm{K}, 10 \mathrm{~mm}$ Tris- $\mathrm{HCl}, \mathrm{pH}$ 7.5), slides were analyze for TUNEL staining using the In situ Cell Death Detection Kit, Fluorescein (Roche). The number of $\mathrm{TUNEL}^{+}$cells on each retinal section containing an injury site was quantified, and the total number of TUNEL $^{+}$cells for each eye was then divided by the number of sections analyzed to give an average number of $\mathrm{TUNEL}^{+}$cells per section containing an injury site.

Imaging and statistics. Slides were examined using a Zeiss Axiophot, Axio Observer Z.1, or an Olympus Fluoview FV1000 laser scanning confocal microscope. Images were captured using a digital camera adapted onto the microscopes. Images were processed and annotated with Adobe Photoshop CS. $p$-values were calculated using Student's $t$ test.

\section{Results}

\section{Genes correlated with DNA demethylation are regulated during retina regeneration}

To begin to characterize the potential role of DNA demethylation during retina regeneration, we determined the transcriptional regulation of the zebrafish Apobec family members (aid, apobec $2 a$, apobec $2 b$ ), Gadd 45 family members ( gadd $45 \alpha, \alpha \mathrm{l}$, $\beta, \beta \mathrm{l}, \gamma, \gamma \mathrm{l})$, DNA glycosylases ( $m b d 4, t d g$ ), DNA methyltransferases $(d n m t 3, d n m t 4)$, and DNA hydroxylases (tet $2 l$, tet 3$)$ during retina regeneration (Fig. $1 \mathrm{~A}$ ). With the exception of aid, all of the transcripts were expressed in the uninjured and injured adult retina. However, only a subset of these genes exhibited injury-dependent regulation (Fig. $1 A, B$ ). The expression of gadd $45 \beta$, gadd $45 \beta 1$, and gadd $45 \gamma$ was induced by $6 \mathrm{~h}$ postinjury (hpi), while the expression of gadd $45 \mathrm{\gamma l}$ was highly induced beginning $\sim 2$ dpi. $t d g, d n m t 3$, dnmt4, and apobec $2 a$ mRNA levels were moderately increased following retinal injury. Interestingly, apobec $2 b$ was highly induced around 6-15 hpi and peaked around 2-4 dpi. Because of the high induction of apobec $2 b$ and because zebrafish Apobecs contribute to DNA demethylation during zebrafish development (Rai et al., 2008), we centered the remainder of our experiments on the regulation and signaling of apobec $2 a$ and $a p o b e c 2 b$ during zebrafish regeneration. 
A

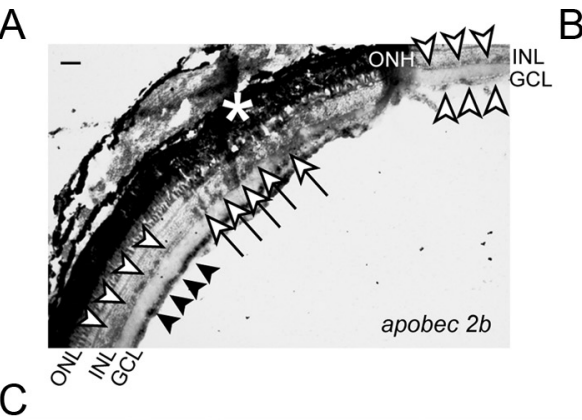

C
B

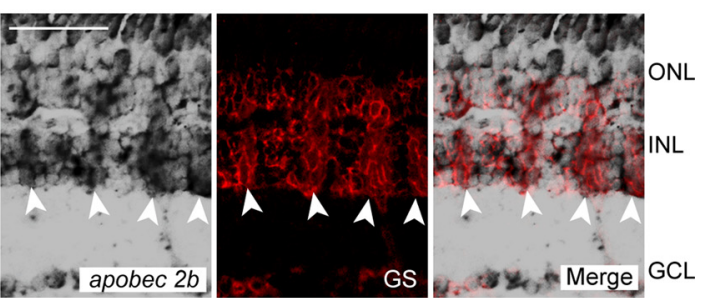

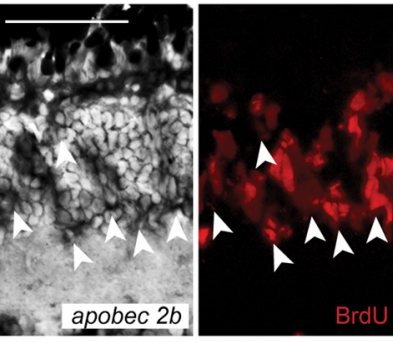

D
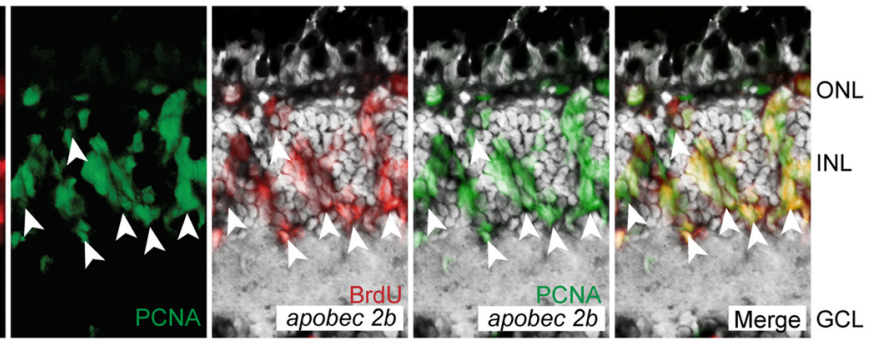

$\mathrm{E}$
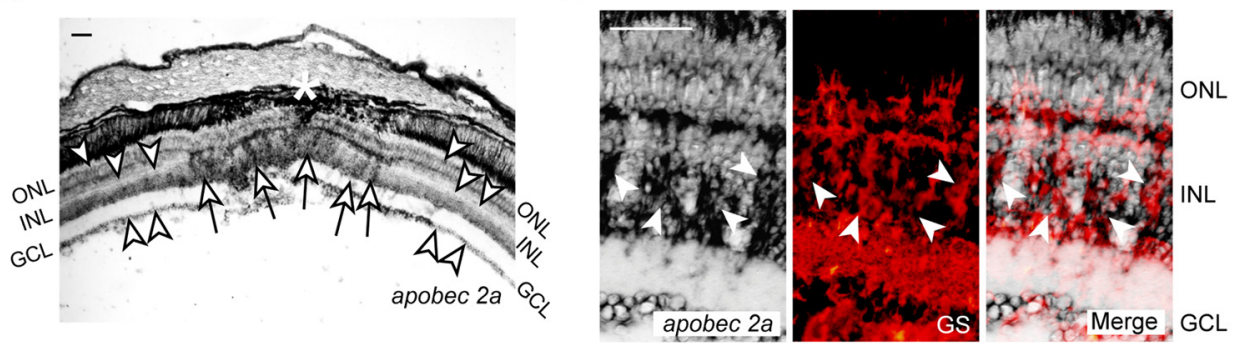

$\mathrm{F}$
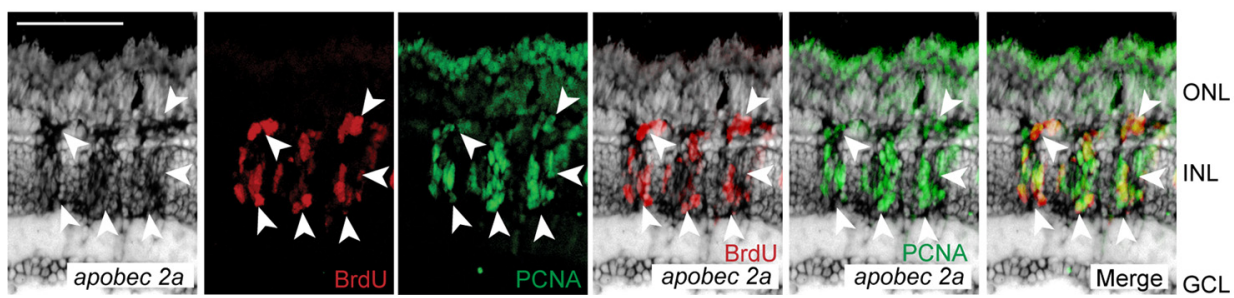

Figure 2. apobec $2 a$ and apobec $2 b$ are induced in proliferating Müller glia following retinal lesion. $A, I n$ situ hybridization at 4 dpi shows injury-dependent induction of apobec $2 b$ mRNA in the INL and GCL. Shown is a representative image of an injury site $\left(^{*}\right)$ and surrounding retina tissue. Cells within the INL that show induced apobec $2 b$ expression at the injury site are marked with white arrows. Injured ganglion cells at and flanking the injury site on the side distal to the $0 \mathrm{NH}$ are distinguished with black arrowheads. Cells in the INL and $\mathrm{GCL}$ expressing basal levels of $a p o b e c 2 b$ are marked with white arrowheads. B, Combined apobec $2 b$ in situ hybridization and GS immunofluorescence shows injury-dependent induction of apobec $2 b$ in Müller glia. White arrowheads indicate colocalization of apobec $2 b \mathrm{mRNA}$ and $\mathrm{GS}{ }^{+}$cells. C, Combined apobec $2 b$ in situ hybridization and BrdU and PCNA immunofluorescence shows injury-dependent induction of apobec $2 b$ in proliferating cells. White arrowheads indicate colocalization of apobec $2 b \mathrm{mRNA}$ in BrdU ${ }^{+}$and PCNA ${ }^{+}$cells. Scale bar, $50 \mu \mathrm{m}$. $\boldsymbol{D}$, In situ hybridization at 4 dpi shows injury-dependent induction of apobec $2 a$ mRNA in the INL. Shown is a representative image of an injury site $\left(^{*}\right)$ and surrounding retina tissue. INL cells that show induced apobec $2 a$ expression at the injury site are marked with white arrows. Cells expressing basal levels of apobec2a are marked with white arrowheads. $E$, Combined apobec2a in situ hybridization and GS immunofluorescence shows injury-dependent induction of apobec2a in Müller glia. White arrowheads indicate colocalization of apobec2a mRNA and GS ${ }^{+}$cells. $F$, Combined apobecza in situ hybridization and BrdU and PCNA immunofluorescence shows injurydependent induction of apobec2a in proliferating cells. White arrowheads indicate colocalization of apobec $2 a$ mRNA in BrdU ${ }^{+}$and PCNA $^{+}$cells. Scale bar, $50 \mu \mathrm{m}$. ONL, Outer nuclear layer.

The increased expression of apobec $2 a$ and apobec $2 b$ after retinal injury is localized to activated Müller glia

Because previous findings largely localized vertebrate Apobec2 to muscle tissue (Etard et al.; Liao et al., 1999; Anant et al., 2001), we sought to confirm our RT-PCR results by examining the spatial pattern of apobec $2 a$ and apobec $2 b$ expression in the retina at $4 \mathrm{dpi}$ using in situ hybridization. Analysis of apobec $2 b$ expression showed injury-dependent transcriptional induction in cells localized to the injury site within the inner nuclear layer (INL) (Fig. $2 \mathrm{~A}$, arrows) and also ganglion cells residing in the ganglion cell layer (GCL) at the injury site and flanking it on the side distal to the optic nerve head (ONH) (Fig. 2A, black arrowheads). On the side of the ONH that did not receive a needle poke injury, we found low levels of apobec $2 b$ expression in cells residing in the GCL and INL (Fig. $2 A$, white arrowheads in upper right corner) similar to what we saw when using in situ hybridization to assay $a p o b e c 2 b$ expression in the uninjured retina. Therefore, it appeared that $a$ pobec $2 b$ was induced in retinal ganglion cells when their axons were severed by the needle poke.

The injury-dependent induction of apobec $2 b$ in the INL at the injury site is characteristic of genes expressed in dedifferentiated and proliferating Müller glia-derived progenitors. To test this idea, fish were injected with BrdU $3.5 \mathrm{~h}$ before harvesting at $4 \mathrm{dpi}$. In situ hybridization assays combined with immunofluorescence 
A

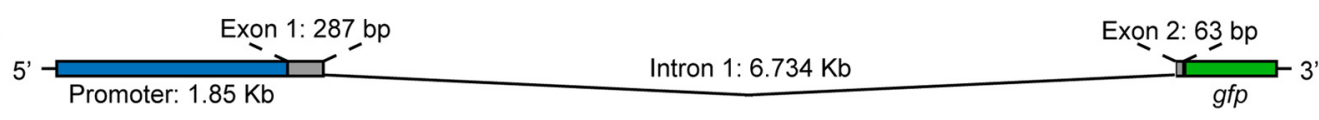

B

C
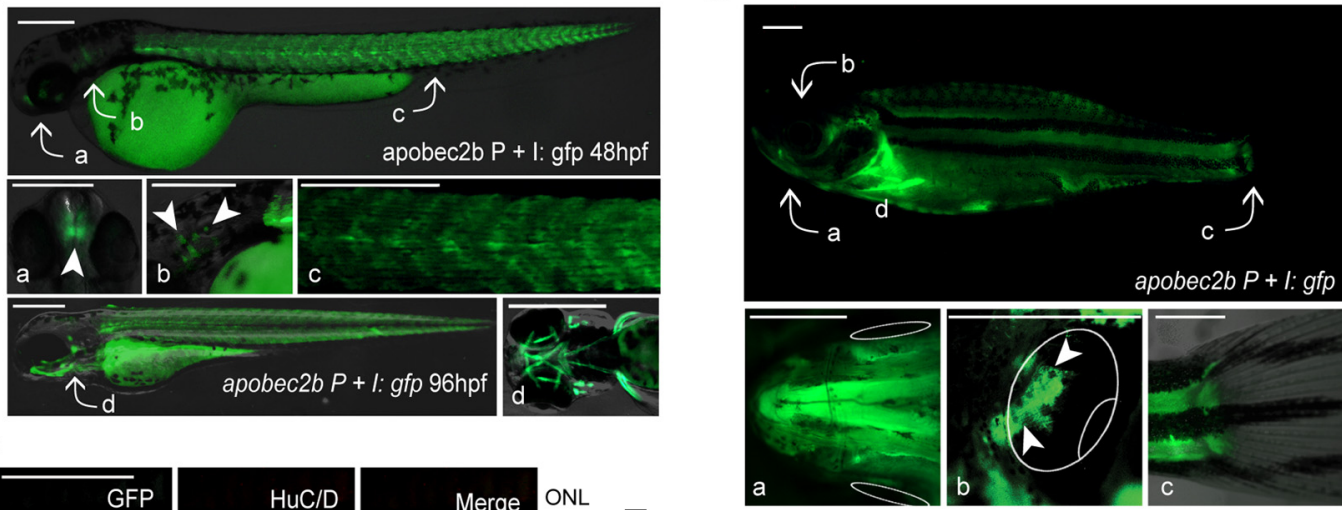

D
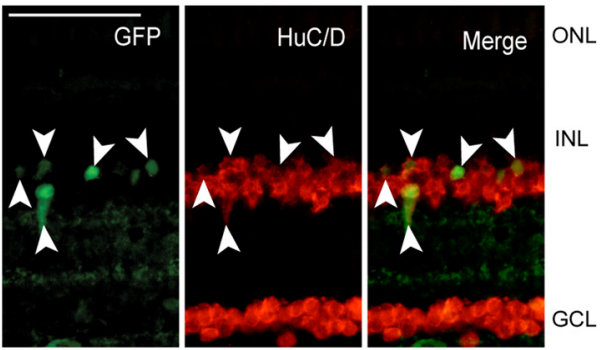

$\mathrm{E}$

G

$\mathrm{F}$
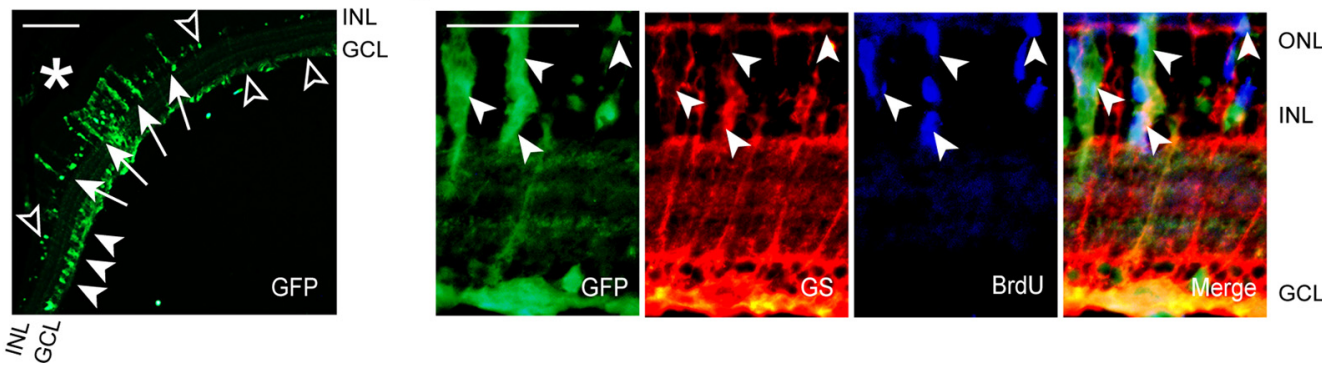

Figure 3. apo $2 b P+$ l:gfp transgenic fish label proliferating Müller glia following injury. $A$, Map of the apo2bP+l:gfp transgene. $B$, Representative images of 48 and $96 \mathrm{~h}$ postfertilization (hpf) apo2bP+ l:gfp transgenic embryos showing GFP expression in the telencephalon $(\boldsymbol{a})$, pharyngeal arches $(\boldsymbol{b})$, somites $(\boldsymbol{c})$, and muscles of the jaw and eyes (d). Scale bar, $400 \mu \mathrm{m}$. $\boldsymbol{C}$, GFP expression in 3-month-old adult apo $2 b P+$ l:gfp transgenic fish. $\boldsymbol{a}$, Ventral view showing expression in the muscles of the jaw and mouth. $\boldsymbol{b}$, Dorsal view showing expression in the muscles of the eye. $\boldsymbol{c}$, Posterior view showing the lack of expression in the caudal fin. $\boldsymbol{d}$, High expression seen in pectoral fin musculature. Scale bar, $1 \mathrm{~mm}$. $\boldsymbol{D}$, Transgene expression in the uninjured retina of adult apo $2 b P+I: g f p$ fish is confined to a subset of HuC/D ${ }^{+}$cells in the INL. Retinal sections were colabeled with antibodies specific for GFP and the amacrine and ganglion cell-specific HuC/D protein. White arrowheads indicate colocalization of GFP ${ }^{+}$and HuC/D ${ }^{+}$cells. Scale bar, $50 \mu \mathrm{m}$. E, Lack of transgene expression in the retina's circumferential germinal zone (CMZ) of adult apo $2 b P+I$ :gfp fish. Retinal sections were examined for GFP and BrdU immunofluorescence. The fish was given an intraperitoneal injection of BrdU $3.5 \mathrm{~h}$ before harvest, and BrdU incorporation identified the CMZ (dotted area). Scale bar, $50 \mu \mathrm{m}$. $\boldsymbol{F}$, Retinal injury in apo2bP +l:gfp fish results in increased transgene expression in the INL and GCL (4 dpi). Shown is an immunofluorescence image using antibodies specific to GFP. Cells within the INL that show induced apobec2b expression at the injury site $\left(^{*}\right)$ are marked with white arrows. Injured ganglion cells are distinguished with white arrowheads. (ells in the INL and GCL expressing basal levels of apobec $2 b$ are marked with black arrowheads. Scale bar, $100 \mu \mathrm{m}$. G, Triple immunofluorescence using antibodies specific to GFP, GS and BrdU shows injury-dependent transgene induction in proliferating Müller glia-derived progenitors. Fish were given an intraperitoneal injection of BrdU $3.5 \mathrm{~h}$ before harvest. White arrowheads indicate colocalization GFP, GS and BrdU. Scale bar, $50 \mu \mathrm{m}$.

against the Müller glia-specific marker GS or the cell proliferation markers BrdU and PCNA showed that these apobec $2 b$-expressing cells were proliferating Müller glia-derived progenitors (Fig. $2 B, C)$. Quantification revealed that $\sim 79 \%$ of the proliferating cells at the injury site expressed apobec $2 b$. apobec $2 b$ expression was largely absent from the proliferating cells of the ciliary marginal zone (CMZ), suggesting that Apobec2b is not needed for stem cell maintenance in the retina (data not shown).

Like apobec $2 b$, analysis of apobec $2 a$ expression 4 dpi showed injury-dependent transcriptional induction in cells localized to the injury site within the INL (Fig. $2 D$, arrows). Low basal levels of apobec $2 a$ expression was seen in all three retinal nuclear layers flanking the injury site (Fig. $2 D$, white arrowheads). In situ hy- bridization assays combined with GS, BrdU, and PCNA immunofluorescence identified the cells with increased apobec $2 a$ expression levels as proliferating Müller glia-derived progenitors (Fig. 2E,F). Quantification revealed that $\sim 76 \%$ of the proliferating cells at the injury site expressed apobec $2 a$.

\section{The promoter of apobec $2 b$ is regulated during retinal} regeneration

To determine whether the injury-dependent induction of $a$ apobec $2 b$ seen by RT-PCR (Fig. 1) results from increased $a p o b e c 2 b$ promoter activity, we generated apobec $2 b P+I: g f p$ transgenic fish that harbor $1.85 \mathrm{~kb}$ of $5^{\prime}$ flanking apobec $2 b$ DNA, exon 1 , intron 1 , and $63 \mathrm{bp}$ of exon 2 in frame with the $g f p$ sequence 
(Fig. 3A). Developmentally, the apobec $2 b P+I: g f p$ transgenic fish showed a $g f p$ expression pattern that was largely localized to the muscle tissue (Fig. 3B) very similar to previously published $a$ pobec $2 b$ expression analyses in zebrafish (Etard et al., 2010; Rai et al., 2010). Adult transgenic fish retained high levels of expression in most muscle tissues including those of the jaw, mouth, eyes, and body. In contrast the fins, operculum, eye, and cranial region of the fish showed little GFP labeling (Fig. 3C). Sections through the adult uninjured retina revealed that basal apobec $2 b$ expression localized to a small population of amacrine cells dispersed throughout the INL as assessed by costaining with the amacrine and ganglion cell-specific $\mathrm{HuC} / \mathrm{D}$ antibody (Fig. 3D). Expression was absent from the CMZ where adult stem cells reside (Fig. 3E). After injury, the apobec $2 b P+I: g f p$ transgenic fish showed a pattern of expression very similar to that of the endogenous apobec $2 b$ gene (compare Figs. $3 F$ and $2 \mathrm{~A}$ ) with transgene induction in pillar-like columns of cells at the site of injury in the INL (white arrows, Fig. $3 F$ ) and in injured ganglion cells (white arrowheads, Fig. 3F). GS and BrdU immunofluorescence showed that $\mathrm{GFP}^{+}$cells in the INL were proliferating Müller glia-derived progenitors (Fig. 3G). Five independent lines showed equivalent staining before and after injury (data not shown), further supporting the evidence of $a p o b e c 2 b$ induction and localization during retina regeneration.

\section{Apobec2a and Apobec2b regulate Müller glia dedifferentiation}

The above data show that the expression of apobec $2 a$ and $a p o b e c 2 b$ is induced early during the process of retina regeneration and is localized to proliferating Müller glia-derived progenitors at $4 \mathrm{dpi}$. Here we tested whether this increase of Apobec $2 \mathrm{a}$ and Apobec2b is necessary for the conversion of the fully differentiated Müller glia to a progenitor state. To this end, we designed lissamine-tagged antisense morpholinos targeting apobec $2 a$ and apobec $2 b$ to knockdown translation of their transcripts during retina regeneration using previously validated morpholino sequences (Rai et al., 2008). To further validate the functionality of the apobec $2 a$ morpholino, a construct was created that harbored the apobec $2 a$ morpholino binding sequence followed by the $g f p$ sequence (pcs $2 \mathrm{p}+$ apobec $2 a$ Mo bs-gfp). The ptal apobec $2 b P+I: g f p$ construct (used for the creation of the transgenic fish) was used to validate $a p o b e c 2 b$ morpholino functionality. Microinjection of these constructs with their respective morpholinos demonstrated a complete GFP knockdown while microinjection with control morpholino had no effect (Fig. $4 A, B)$. To determine the efficiency of morpholino knockdown in an injured retina, Apobec $2 \mathrm{a}$ and Apobec $2 \mathrm{~b}$ protein levels were measured $4 \mathrm{~d}$ after administration and electroporation of 0.25 mu morpholino. Treatment with apobec $2 a$ or apobec $2 b$ morpholino resulted in an approximate $35 \%$ and $70 \%$ knockdown in their protein levels relative to a control, respectively (Fig. 4C,D). Both Apobec2a and Apobec2b protein is found basally in the retina, and their levels increase according to their mRNA induction following injury (data not shown). The apparent low efficiency of Apobec2a knockdown compared with Apobec $2 b$ is likely due to the lower level of apobec $2 a$ induction at the site of injury where the morpholino is present. Thus, the basal Apobec2a levels present in the uninjured, morpholino deficient portion of the retina likely partially mask the effect of the morpholino. Finally, treatment of the apobec $2 b P+I: g p f$ with $a p o b e c 2 b$ morpholino largely blocked the induction of the transgene at the site of injury (Fig. $4 E$ ).

To determine the impact of Apobec2a and Apobec2b knockdown on retina regeneration, we first analyzed the impact of mor-
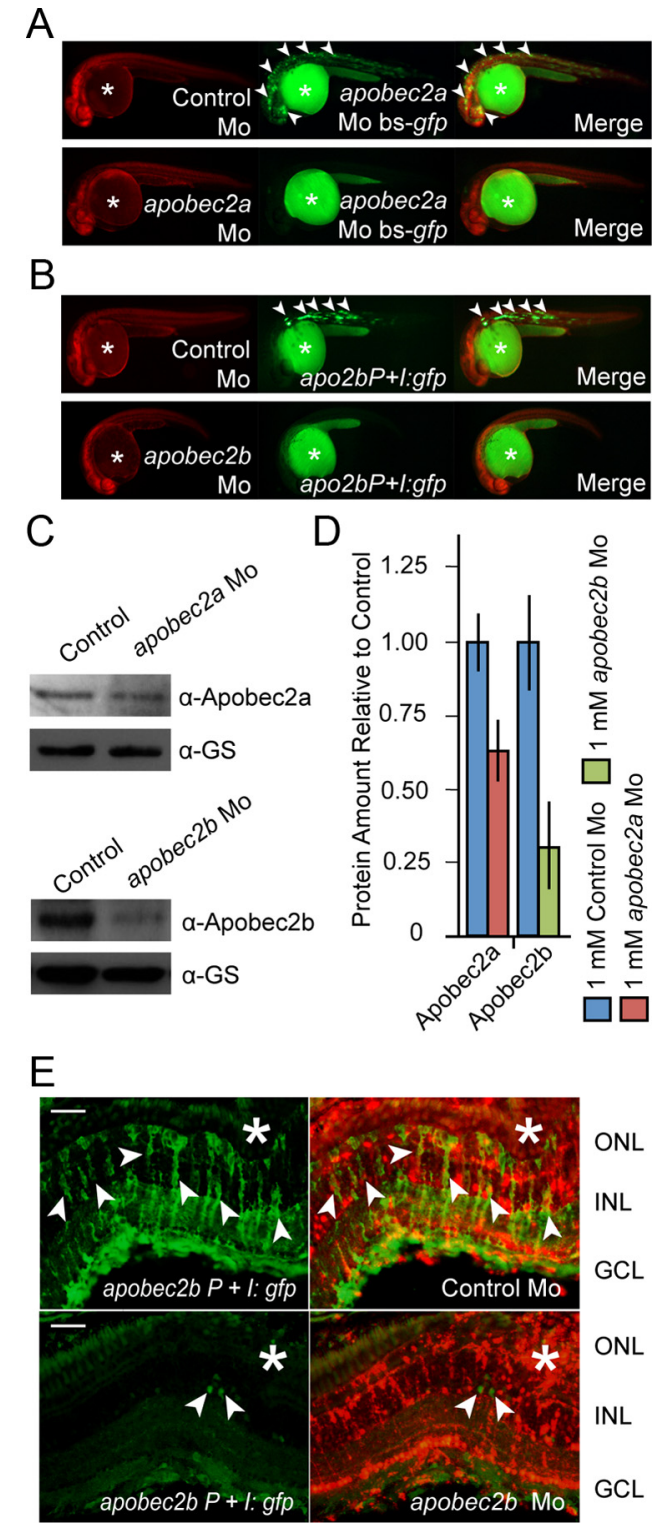

Figure 4. Validation of apobec $2 a$ and apobec $2 b$ morpholinos. $A$, Twenty-four hour postfertilization embryos microinjected at the single cell stage with pcs $2 p+$ apobec $2 a$ Mo bs-gfp (expression vector with apobec $2 \mathrm{a}$ Mo target sequence appended to the $\mathrm{N}$ terminus of GFP) in combination with lissamine tagged Control or apobec $2 a$ Mo showing knockdown of GFP with the apobec $2 a$ Mo but not the Control Mo. An asterisk marks autofluorescence in the zebrafish yolk sac. $\boldsymbol{B}$, Twenty-four hour postfertilization embryos microinjected at the single cell stage with ptal apobec $2 b P+$ l:gfp in combination with lissamine tagged Control or apobec $2 b \mathrm{Mo}_{0}$ showing knockdown of GFP with the apobec $2 b$ Mo but not the Control. An asterisk marks autofluorescence in the zebrafish yolk sac. C, Western blot of protein isolated from a $4 \mathrm{~d}$ postinjury retina showing knockdown of Apobec $2 \mathrm{a}$ and Apobec $2 \mathrm{~b}$ by their respective morpholinos. GS served as a loading control. D, Quantification of Apobec2a and Apobec2b knockdown after morpholino treatment. Densitometry was calculated from Western blots using ImageJ. $y$-axis is relative protein amount and is normalized to the control, which was assigned a value of 1. GS served as the internal control (Control and Apobec $2 \mathrm{a}, n=3$ individual retinas; Apobec $2 \mathrm{~b}, n=$ 2 individual retinas). $\boldsymbol{E}$, GFP immunofluorescence shows apobec $2 b$ Mo treatment suppresses injury-dependent GFP expression in apobec $2 b P+$ l:gfp transgenic fish. Eyes were isolated $4 \mathrm{~d}$ postinjury. The injury site is marked with an asterisk. Arrowheads indicate GFP ${ }^{+}$cells within INL harboring lissamine-tagged morpholino. Scale bar, $50 \mu \mathrm{m}$. ONL, Outer nuclear layer.

pholino incorporation on GFP transgene expression in 1016 tubala: gfp transgenic fish which was previously shown to label dedifferentiated Müller glia in the injured retina (Fausett and Goldman, 2006; Fausett et al., 2008; Ramachandran et al., 2010b). Fish 
A
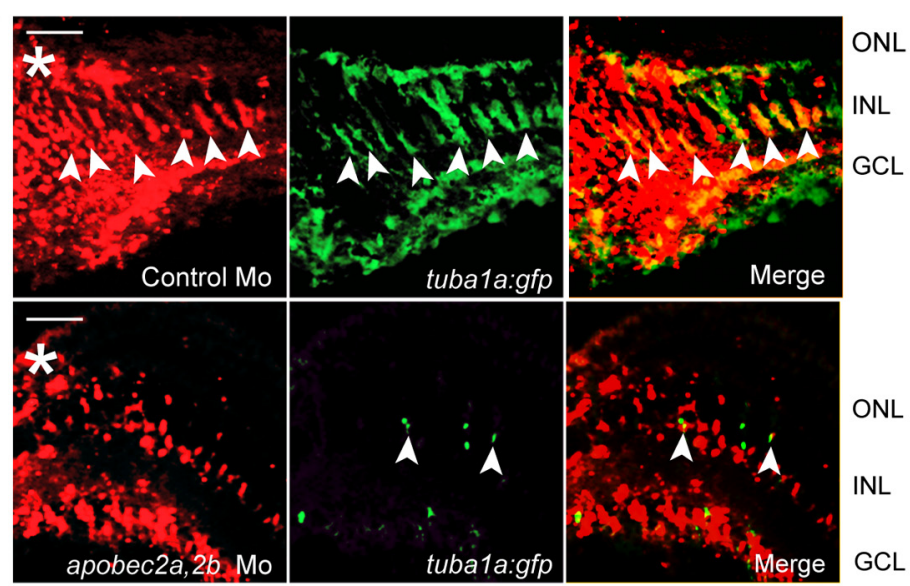

B
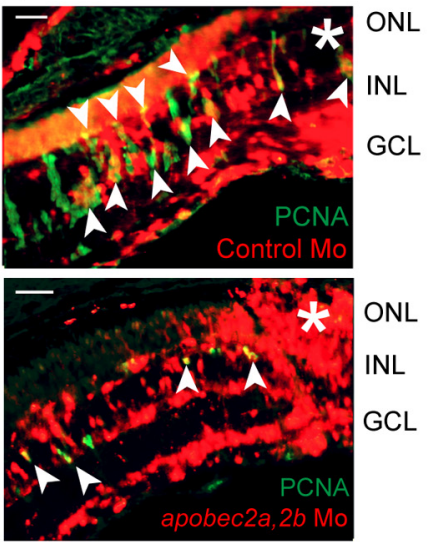

$\mathrm{E}$
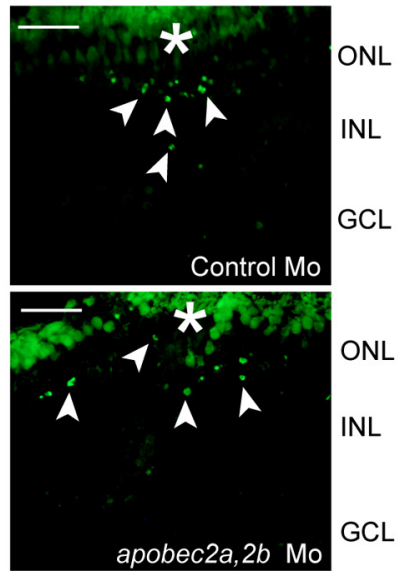

C
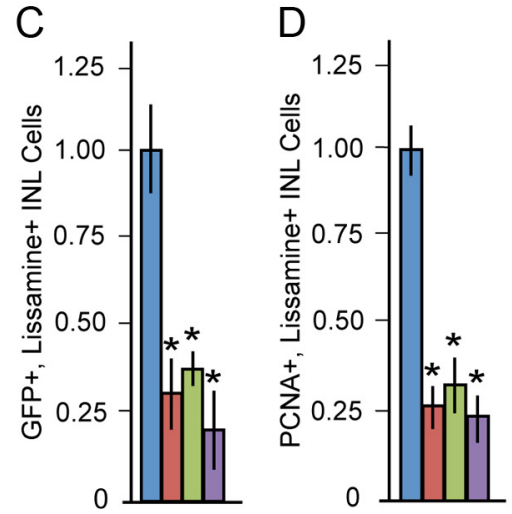

口 Control Mo

口 apobec $2 b$ Mo

apobec2a Mo $\square$ apobec2a,2b Mo

F

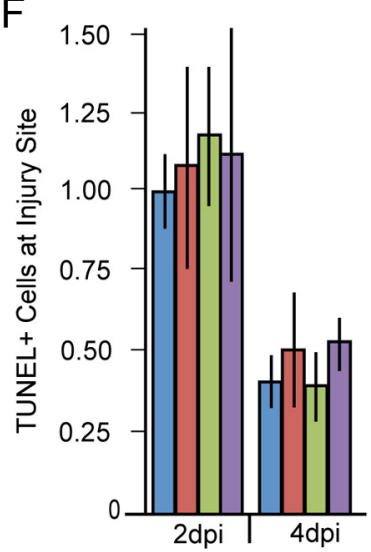

Figure 5. Knockdown of Apobec2a or Apobec2b blocks 1016 tuba1a:gfp transgene expression and Müller glia-derived progenitor proliferation. $\boldsymbol{A}$, GFP immunofluorescence shows Apobec2a,2b knockdown suppresses injury-dependent GFP expression in 1016 tuba1a:gfp fish. Arrowheads indicate GFP ${ }^{+}$cells within INL harboring lissamine-tagged morpholino. Eyes were isolated $4 \mathrm{~d}$ postinjury. Scale bar, $50 \mu \mathrm{m}$. B, PCNA immunofluorescence shows Apobec2a,2b knockdown suppresses cell proliferation in the injured retina. Arrowheads indicate PCNA ${ }^{+}$cells within the INL harboring lissamine-tagged morpholino. Eyes were isolated $4 \mathrm{~d}$ postinjury. Scale bar, $50 \mu \mathrm{m}$. $C, D$, Quantification of the fraction of the total number of morpholino-positive cells within the INL that are GFP (1016 tuba1a:gfp) positive (C) or are proliferating (wt) as indicated by PCNA staining (D) following Apobec2a, Apobec2b, or Apobec2a,2b knockdown. The data were normalized to the value of the control Mo, which was given a value of 1 . Data represent means $\pm S D$ ( $n=3$ individual fish; compared with control Mo, apobec $2 a$, apobec $2 b$, and apobec $2 a, 2 b$ Mo oligonucleotides, ${ }^{*} p<0.0012$ for GFP and ${ }^{*} p<0.0002$ for PCNA quantifications). $\boldsymbol{E}$, TUNEL staining identifies cells undergoing apoptosis at the site of injury $\left(^{*}\right)$ following treatment with Control or apobec $2 a$ and apobec $2 b$ Mo. Eyes were isolated $2 \mathrm{~d}$ postinjury. Arrowheads indicate TUNEL ${ }^{+}$cells. $\boldsymbol{F}$, Quantification of the TUNEL $^{+}$cells at the site of injury. Samples were isolated 2 and $4 \mathrm{~d}$ postinjection and electroporation of the indicated morpholino. The data were normalized to the value of the control morpholino at $2 \mathrm{dpi}$, which was given a value of 1. Data represent means \pm SD ( $n=3$ individual fish). ONL, Outer nuclear layer.

eyes were injected at the time of injury with $0.25 \mathrm{~mm}$ lissamine-tagged control or 0.25 mM lissamine-tagged apobec $2 a, 2 b$-targeting morpholinos $(0.125 \mathrm{~mm}$ apobec $2 a$ and apobec $2 b$ morpholino). As shown previously, administration of the control morpholino had no noticeable effect on transgene induction following injury (Fig. $5 A$, top). Strikingly, when Apobec $2 \mathrm{a}$ and Apobec $2 b$ were knocked down, transgene expression was dramatically reduced in the lissamine-positive INL cells when compared with the control (Fig. 5A, bottom, $C$ ). When we analyzed the effect of each morpholino individually (injections of $0.25 \mathrm{~mm}$ apobec $2 a$ or $0.25 \mathrm{~mm}$ apobec $2 b$ morpholino) on the process of regeneration, we were surprised to see that 1016 tubala:gfp transgene expression was suppressed in both cases (Fig. 5C) suggesting that these proteins do not act redundantly.

To confirm these results, we repeated these morpholino knockdown experiments using wild-type zebrafish to determine whether the knockdown of Apobec $2 \mathrm{a}$, Apobec2b, or Apobec $2 a$ and Apobec $2 b$ would inhibit the proliferation of Müller glia-derived progenitors using PCNA immunofluorescence as a marker of dividing cells. As seen with tubala:gfp transgene expression, PCNA labeling was greatly reduced upon injection of any of the experimental morpholinos (Fig. $5 B, D$ ). These results indicate that both Apobec $2 a$ and Apobec $2 b$ regulate dedifferentiation and proliferation of Müller glia following injury.

We were curious to know whether this reduced regenerative response seen after knockdown of Apobec proteins could be attributed to increased cell death at the site of injury. TUNEL assays were performed to measure cell death by apoptosis following morpholino treatment and knockdown. No difference was seen between control and experimental knockdown at 2 or $4 \mathrm{~d}$ following injury (Fig. $5 E, F$ ). Similar results were seen after staining for activated caspase-3 (data not shown).

\section{Asclla activates apobec $2 \mathrm{~b}$ expression during retina regeneration}

We next investigated potential mechanisms underlying the injury-dependent activation of apobec $2 a$ and apobec $2 b$. Previous studies suggested that in zebrafish $c e b p \beta$ overexpression increased the expression of multiple genes correlated with DNA demethylation developmentally, including apobec $2 a$ and apobec $2 b$ (Rai et al., 2010). Therefore, we assayed the transcriptional regulation of $c e b p \beta$ following retina injury and compared it with other 
A

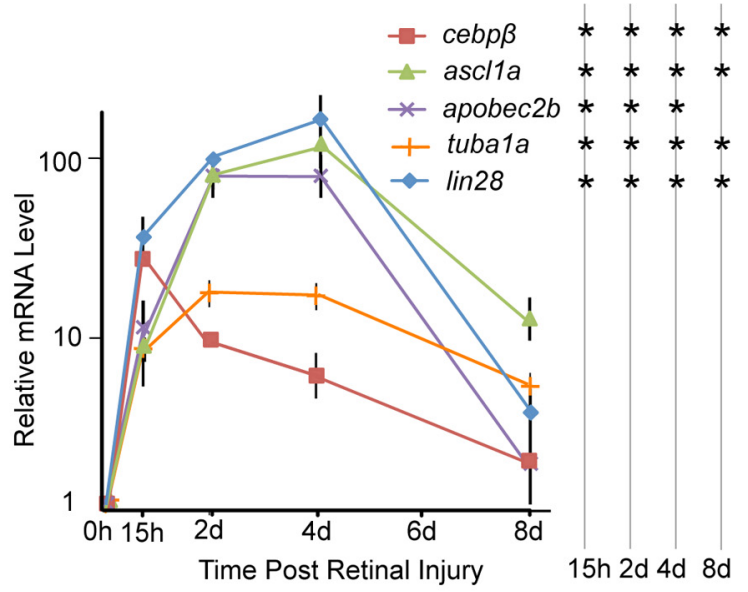

B
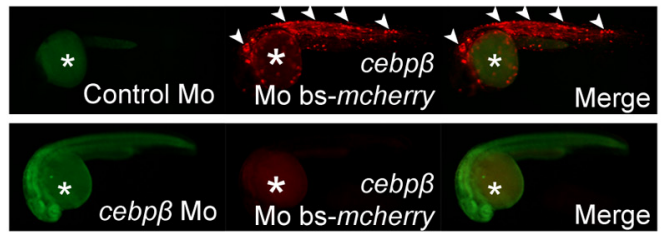

C

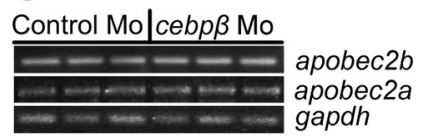

D

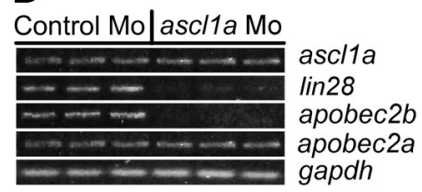

E

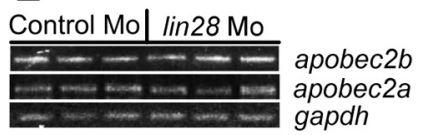

G

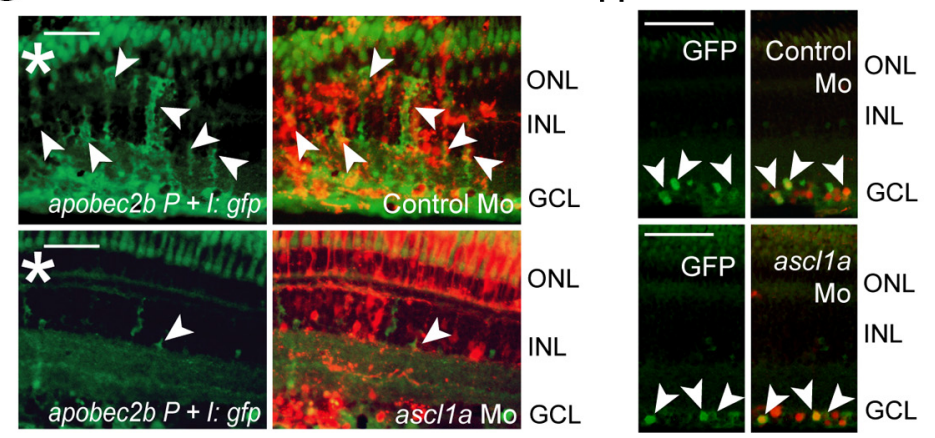

Figure 6. Injury-dependent Ascl1a signaling results in the increased expression of apobec $2 b$. A, Real-time PCR quantification of indicated mRNAs isolated from retina at various times postinjury ( $x$-axis). $y$-axis is fold induction in log scale and is normalized to $0 \mathrm{~h}(0 \mathrm{~h}$, i.e., uninjured control) which was assigned a value of 1 . The expression of gapdh served as the internal control. Data represent means $\pm S D$ ( $n=3$ individual cDNA sets; compared with control, time points marked with an asterisk have a $p<$ 0.037). $\boldsymbol{B}$, Twenty-four hour postfertilization embryos microinjected at the single cell stage with cebp $\beta$ Mo bs- $m$ Cherry (expression vector harboring Mo target sequence appended to the $\mathrm{N}$ terminus of $\mathrm{m}$ (herry) in combination with untagged (ontrol or fluorescein tagged cebp $\beta$ Mo showing knockdown of $\mathrm{mCherry}$ with the cebp $\beta$ morpholino but not the Control. An asterisk marks autofluorescence in the zebrafish yolk sac. C, RT-PCR indicates Cebp $\beta$ knockdown has no effect on injury-dependent apobec2a or apobec $2 b$ expression at 2 dpi. $\boldsymbol{D}, \mathrm{RT}$-PCR indicates Ascl1a knockdown blocks injury-dependent induction of lin2 28 and apobec $2 b$ mRNAs at 2 dpi. $\boldsymbol{E}$, Lin28 knockdown shows no effect on injury-dependent induction of apobec $2 a$ and apobec $2 b$ mRNAs at $2 \mathrm{dpi}$. $\boldsymbol{C}-\boldsymbol{E}$, Each regeneration-associated genes. Interestingly, $\operatorname{cebp} \beta$ was induced very early after injury, peaking around $15 \mathrm{hpi}$ and then declining (Fig. 6A). Most importantly, $c e b p \beta$ induction appeared to coincide with the induction of apobec $2 b$ and other regeneration-associated genes like tubala, asclla, and lin28 (Fausett et al., 2008; Ramachandran et al., 2010b). To test whether this induction was necessary for injury-dependent apobec $2 a$ and $a p o b e c 2 b$ expression, $\operatorname{Cebp} \beta$ was knocked-down by administration of a previously validated cebp $\beta$-specific antisense morpholino oligonucleotide (Rai et al., 2010). The functionality of the $c e b p \beta$ morpholino was validated through the creation of a construct harboring the binding sequence followed by the mCherry sequence ( $\mathrm{pcs} 2 \mathrm{p}+$ cebp $\beta$ Mo bs-mCherry, Fig. 6B). Following knockdown of $\operatorname{Cebp} \beta$ during retina regeneration, gene expression was assayed 2 dpi when Müller glia are dedifferentiating and just beginning to enter the cell cycle (Fausett and Goldman, 2006). Surprisingly, $\operatorname{Cepb} \beta$ knockdown had no discernable effect on apobec $2 a$ or apobec $2 b$ expression in the injured retina (Fig. 6C,F).

In addition to $\operatorname{Cebp} \beta$, others have reported that human APOBEC2 expression is enhanced by NF- $\kappa \mathrm{B}$ signaling (Matsumoto et al., 2006). To test whether NF- $\kappa \mathrm{B}$ signaling operates in the zebrafish retina to regulate injury-dependent apobec $2 b$ expression, zebrafish eyes were injected intravitreously with chemical inhibitors of NF- $\kappa \mathrm{B}$ signaling, wedelolactone or ethyl pyruvate (Daroczi et al., 2009), at the time of injury, and the expression of apobec $2 a$ and $a p o b e c 2 b$ was assessed $2 \mathrm{~d}$ later. No

$\longleftarrow$

agarose gel lane represents a sample prepared from an independent fish. The expression of gapdh served as the internal control. $\boldsymbol{F}$, Real-time PCR quantification of apobec $2 a$ and apobec $2 b$ mRNA levels after injury and treatment with the indicated morpholinos. ascl1a Mo 1 is specific to its ATG translational start region and ascl1a Mo 2 is specific to its $5^{\prime}$ UTR. The mRNA fold induction was normalized to the value of the control morpholino, which was given a value of 1 . gapdh served as the internal control. Data represent means $\pm \mathrm{SD}(n=3$ individual fish; compared with control Mo, ascl1a Mo 1 and 2, $\left.{ }^{*} p<0.01\right)$. G, GFP immunofluorescence shows ascl1a Mo treatment suppresses injury-dependent GFP expression in cells of the INL of apobec $2 b P+$ l:gfp transgenic fish. Eyes were isolated at $3 \mathrm{dpi}$. The injury site is marked with an asterisk. Arrowheads indicate GFP ${ }^{+}$cells within INL harboring lissamine-tagged morpholino. Scale bar, $50 \mu \mathrm{m}$. $\boldsymbol{H}, \mathrm{GFP}$ immunofluorescence shows asclia Mo treatment has no impact on injury-dependent GFP expression in injured ganglion cells of apobec $2 b P+l$ :gfp transgenic fish. Shown is a region flanking an injury site. Eyes were isolated at $3 \mathrm{dpi}$. Arrowheads indicate $\mathrm{GFP}^{+}$cells within $\mathrm{GCL}$ harboring lissamine-tagged morpholino. Scale bar, $50 \mu \mathrm{m}$. 
A

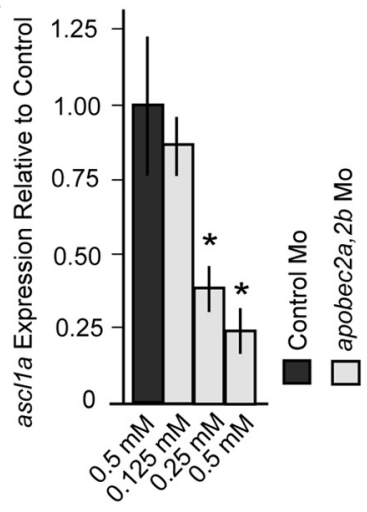

$\mathrm{B}$

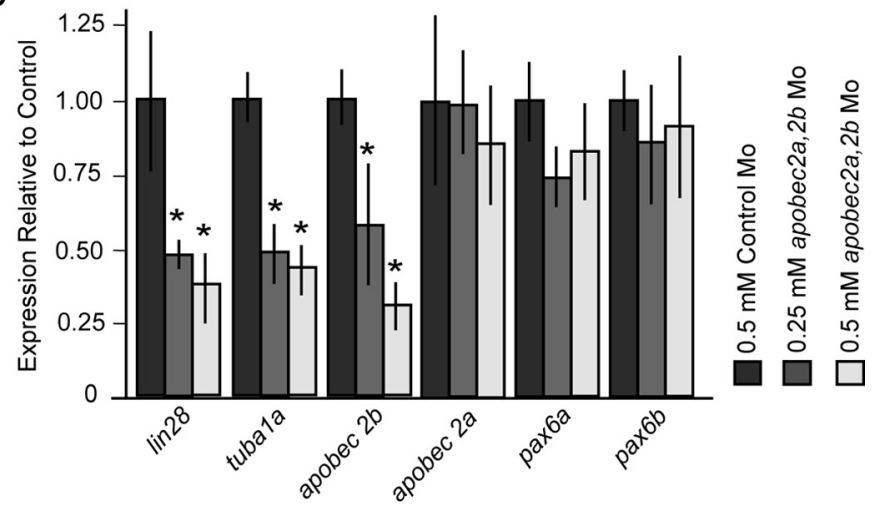

C

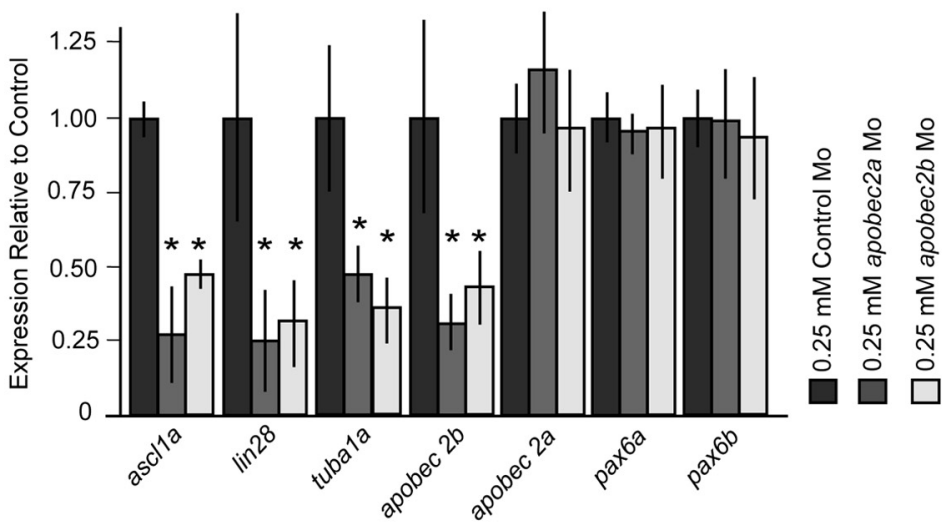

$\mathrm{D}$

$\mathrm{E}$
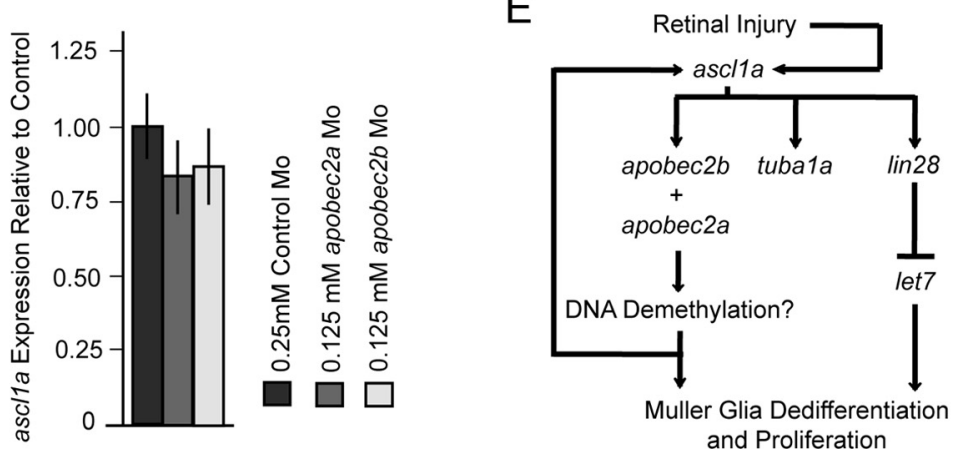

Figure 7. Apobec2a and Apobec2b regulate injury-dependent ascl1a, lin28, and tuba1a expression. $\boldsymbol{A}-\boldsymbol{D}$, Real-time PCR quantification of the effects of Apobec2a and Apobec2b knockdown either together $(\boldsymbol{A}, \boldsymbol{B})$ or individually $(\boldsymbol{C}, \boldsymbol{D})$ on the indicated mRNAs. mRNA levels were normalized to the control Mo, which was given a value of 1 . The expression of gapdh served as the internal control. Data represent means \pm SD. $A$, Knockdown of Apobec2a and Apobec $2 b$ blocks injury-dependent ascl 1 a induction ( $n=3$ individual fish; compared with control Mo, apobec2a, $2 b$ Mo* $p<$ 0.011). B, Knockdown of Apobec2a and Apobec $2 b$ blocks injury-dependent induction of lin28, tuba 1a, and apobec $2 b$ ( $n=3$ individual fish; compared with control Mo, apobec $2 a, 2 b$ Mo knockdown of $\operatorname{lin} 28^{*} p<0.018$, knockdown of tuba1 ${ }^{*} p<0.004$, knockdown of apobec $2 b{ }^{*} p<0.027$ ). C, Knockdown of Apobec2a and Apobec2b independently shows similar effects on gene expression as knocking them both down together $(n=3$ individual fish; compared with control morpholino, apobec $2 a$ and apobec $2 b$ Mo individually block the induction of lin28, tuba $a$, and $a p o b e c 2 b * p<$ 0.04). $\boldsymbol{D}$, The decreased expression of ascl $7 a$ after the independent knockdown of Apobec $2 \mathrm{a}$ and Apoc $2 \mathrm{~b}$ is concentration dependent, as lower concentrations of morpholino do not significantly alter asclia levels. E, Summary of knockdown data placed in context of known signaling during retina regeneration.

difference between drug- and vehicle-injected samples was observed (data not shown).

Next, we looked for the regulation of apobec $2 a$ and $a p o b e c 2 b$ expression by genes that are induced in dedifferentiating Müller glia very early following retinal injury and that are required for regeneration. One such gene is asclla whose expression is induced within 4 hpi and is represented in $\sim 80 \%$ of the Müller glia-derived progenitors (Fausett et al., 2008; Ramachandran et al., 2010b). The injury-dependent increase of $a p o b e c 2 b$ largely parallels the induction of asclla and its downstream targets tubala (Fausett et al., 2008) and lin28 (Ramachandran et al., 2010b) (Fig. 6A). To determine whether Asclla regulates apobec $2 a$ and/or apobec $2 b$ expression in the injured retina, we knocked down its expression with previously validated ascllatargeting morpholinos (Fausett et al., 2008; Ramachandran et al., 2010b). Interestingly, the induction of apobec $2 b$, but not apobec $2 a$, was significantly attenuated following Asclla knockdown (Fig. 6D,F). However, knockdown of Lin28 had no noticeable impact on apobec $2 b$ expression (Fig. 6E,F), suggesting that Asclla/Apobec2b signaling is a novel, previously uncharacterized, signaling pathway stemming from Asclla.

Knockdown of Asclla in the apobec $2 b P+I: g f p$ transgenic fish largely blocked the induction of the transgene in the INL (Fig. $6 G$ ) but had no noticeable impact on the transgene levels in gan- 
glion cells whose axons where injured with poke (Fig. $6 H$ ) suggesting that Asclla signaling does not activate apobec $2 b$ expression in injured ganglion cells. Overexpression of asclla during zebrafish development did not show a significant increase in apobec $2 b$ mRNA 2 d postfertilization or a noticeable increase of GFP in the apobec $2 b P+I: g f p$ transgenic fish suggesting that the Asclla/Apobec2b signaling cascade may be specifically operative in the regenerating retina (data not shown).

Apobec2a and Apobec2b participate in a feedback loop to regulate asclla during retina regeneration

We next sought to identify genes whose expression is regulated by Apobec $2 \mathrm{a}$ and/or Apobec $2 b$ signaling. These efforts were complicated due to the lack of a clear molecular function of Apobec 2 proteins and no known targets of their signaling. We began by analyzing the impact of Apobec2a and Apobec $2 b$ knockdown on the expression of genes transcriptionally induced at or before $2 \mathrm{dpi}$. Those assayed included: ascl1a, $\operatorname{lin} 28$, klf4, oct4, olig2, atoh, tubala, tuba1b, nanog, dnmt4, pax6a, and pax6b. Interestingly, when Apobec2a and Apobec2b were knocked down, the transcriptional induction of ascllawas reduced in a concentrationdependent manner (Fig. 7A). In addition, the induction of the Asclla target genes lin 28 , tuba1 $a$, and $a p o b e c 2 b$ were attenuated while injury-dependent induction of pax $6 a$ and pax $6 b$ remained unaffected (Fig. $7 B$ ). Apobec2a and Apobec2b knockdown had no detectable effect on atoh, oct4, olig2, klf4, tuba1b, dnmt4, and nanog expression (data not shown). Similar results were seen when Apobec2a or Apobec $2 b$ was knocked down individually at concentrations of 0.25 mM (Fig. 7C), but lower concentrations showed no effect (Fig. 7D). These results indicate that a feedback mechanism exists between Asclla and Apobec2b/Apobec2a (Fig. 7E).

Knockdown or overexpression of Apobec2a and Apobec2b did not have a significant impact on the levels of asclla mRNA in developing zebrafish 2 d postfertilization (data not shown), indicating that the feedback regulation observed in the adult retina is specific to retina regeneration.

ascl1a and apobec $2 \mathrm{~b} \mathrm{mRNAs}$ are regulated during optic nerve regeneration

Curiously, apobec $2 b$ appeared to be induced in retinal ganglion cells when optic axons were injured with a needle poke (Figs. $2 \mathrm{~A}$, $3 F$ ). Indeed, we found that optic nerve lesion-induced $a p o b e c 2 b$ expression in retinal ganglion cells (Fig. 8). The expression of apobec $2 b$ increased during the first $24 \mathrm{~h}$ following optic nerve

A

B

C
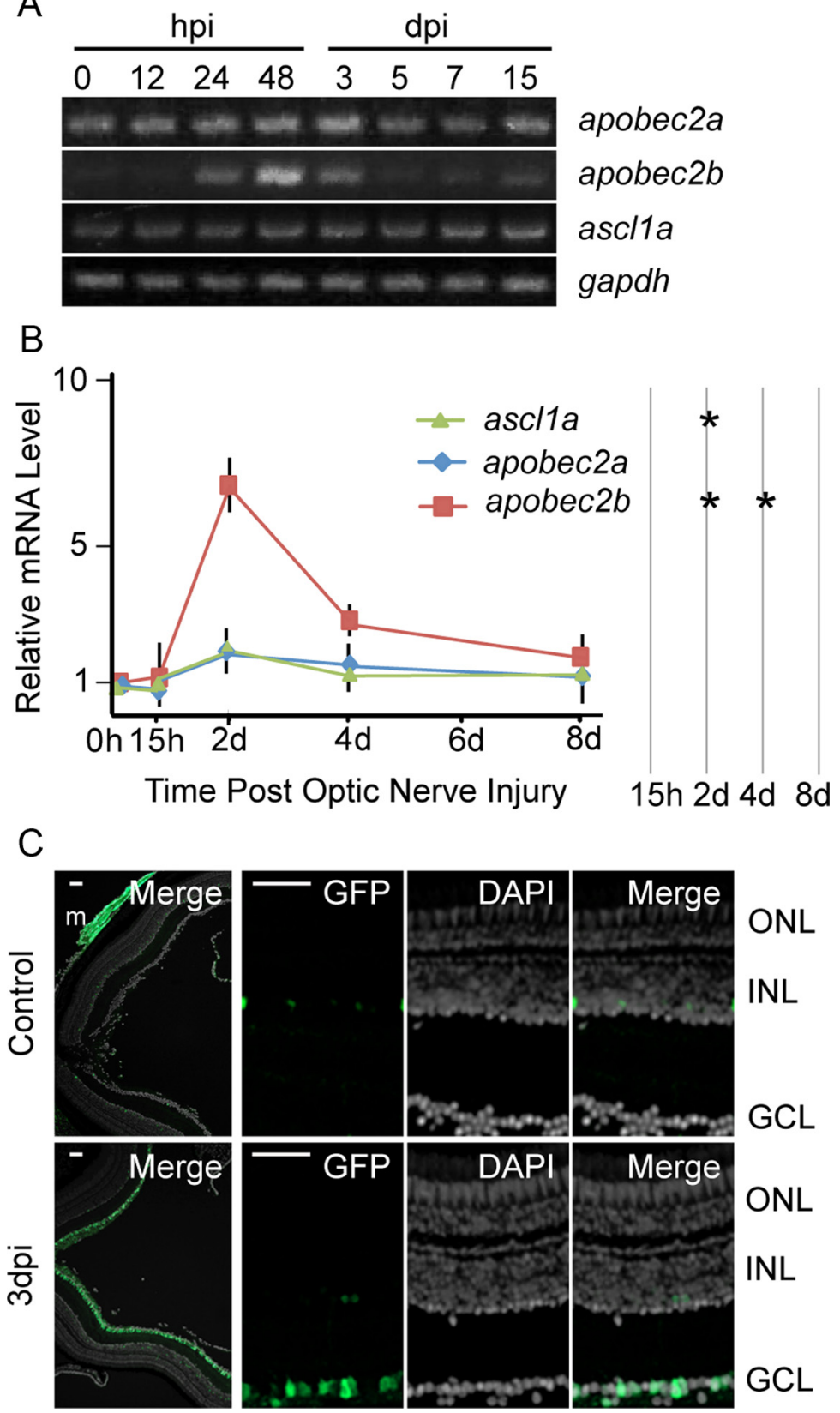

Figure 8. apobec $2 b$ and ascl $1 a$ mRNA levels are induced during optic nerve regeneration. $A, R T-P C R$ analysis of indicated mRNAs isolated from the retina at various times after optic nerve lesion. The expression of gapdh served as the internal control. One representative of three independent time courses is shown. $\boldsymbol{B}$, Real-time PCR quantification of indicated mRNAs levels isolated from retina at the indicated times postinjury ( $x$-axis). $y$-axis is normalized to $0 \mathrm{~h}(0 \mathrm{~h})$, i.e., the uninjured retina, which was assigned a value of 1 . The expression of gapdh served as the internal control. Data represent means \pm SD ( $n=3$ individual cDNA sets; compared with control, time points marked with an asterisk have a $p<0.0053$ ) C, GFP immunofluorescence shows injury-dependent transgene induction in retinal ganglion cells of apo2bP+l:gfp transgenic fish at $3 \mathrm{dpi}$. GFP expression in an ocular muscle exterior to the eye is marked with an " $\mathrm{m}$ " in the control (top) panel. Scale bar, $50 \mu \mathrm{m}$. 0NL, Outer nuclear layer.

lesion and reached its peak around $2 \mathrm{dpi}$ (Fig. $8 A, B$ ). Optic nerve lesion in $a p o 2 b P+I: g f p$ transgenic fish showed that apobec $2 b$ promoter activity was increased in retinal ganglion cells that were regenerating their optic axons (Fig. $8 C$ ). apobec $2 a$ expression was largely uninduced during optic nerve regeneration (Fig. 8A,B).

During retina regeneration, apobec $2 b$ induction was dependent on Asclla expression (Fig. 6D,F). Surprisingly, we found that the expression of asclla was slightly induced following optic nerve cut (Fig. $8 A, B$ ). To determine whether Asclla signaling was necessary 
A

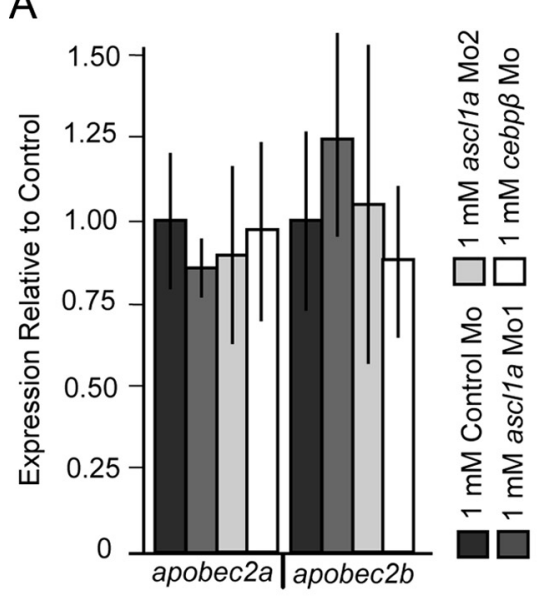

C

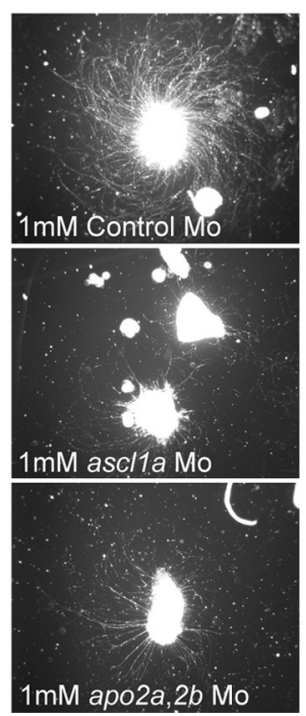

B

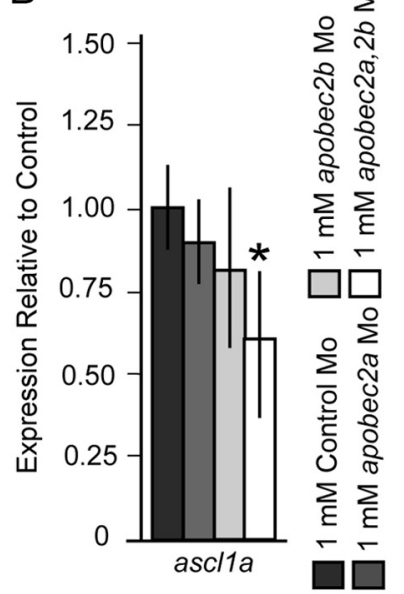

D
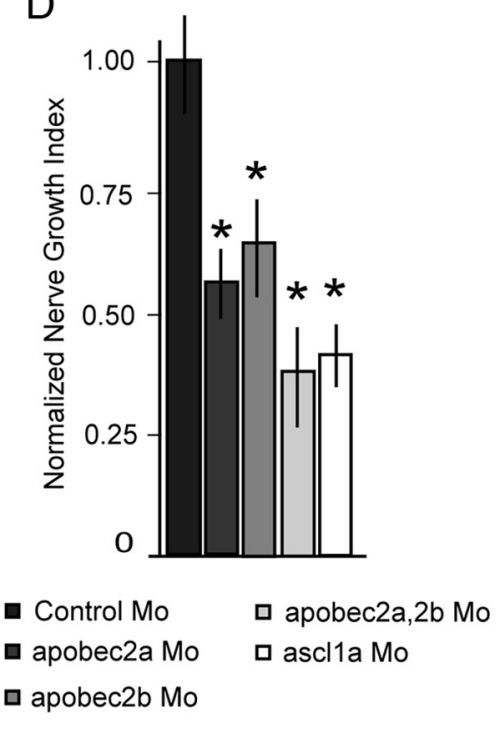

Figure 9. Ascl1a, Apobec $2 a$, and Apobec $2 b$ regulate axonal growth during optic nerve regeneration. The indicated morpholinos (1 $\mathrm{mm}$ ) were delivered to retinal ganglion cells in vivo by placing morpholino-soaked Gelfoam on the optic nerve stump following lesion. $\boldsymbol{A}, \boldsymbol{B}$, Retinas were isolated $2 \mathrm{~d}$ after optic nerve lesion and morpholino treatment for expression analysis. The expression of gapdh served as the internal control. The data were normalized to the value of the control Mo, which was given a value of $1 . \boldsymbol{A}$, Knockdown of Cebp $\beta$ or Ascl1a did not significantly affect apobec $2 a$ or apobec $2 b$ expression. Data represent means \pm SD $(n=3$ individual fish). $\boldsymbol{B}$, Knockdown of Apobec2a and Apobec $2 b$, but not each individually, reduced the levels of ascl1a. Data represent means \pm SD $(n=3$ individual fish for the apobec $2 a$ and apobec $2 b$ Mo samples, $n=4$ individual fish for Control and $a p o b e c 2 a, 2 b$ Mo samples; compared with Control Mo, apobec $2 a, 2 b$ Mo knockdown of ascl1a $\left.{ }^{*} p<0.024\right)$. C, Representative images of axonal outgrowth following treatment with the indicated morpholinos. Retinas were isolated $4 \mathrm{~d}$ after morpholino treatment, diced, and cultured for $4 \mathrm{~d}$ before analysis of neurite outgrowth. D, Quantification of Nerve Growth Index (see Material and Methods) values following morpholino treatment and explant. Values were normalized to Control Mo-treated samples, which were given a value of 1. Data represent means \pm SD ( $n=3$ individual fish for Control, ascl1a, and apobec $2 a, 2 b$ Mo samples; $n=4$ individual fish for apobec $2 a$ and apobec $2 b$ Mo samples; compared with control Mo, samples marked with an asterisk have a $p<0.01$ ).

for the induction of apobec $2 b$ during optic nerve regeneration, Asclla was knocked down with asclla-targeting morpholinos applied to the lesioned optic nerve stump as previously described (Veldman et al., 2007, 2010). Two days after optic nerve lesion, injury-dependent induction of apobec $2 b$ was quantified. Asclla knockdown had no apparent effect on injury-dependent apobec $2 b$ induction following optic nerve lesion (Fig. 9A). This is similar to what we saw in the ganglion cells that were injured after injection of apobec $2 b P+I: g f p$ transgenic fish with the asclla Mo (Fig. $6 H$ ). Likewise, $\operatorname{Cebp} \beta$ knockdown had no impact on $a p o b e c 2 b$ induction (Fig. $9 A)$. Interestingly, when we knocked down Apobec $2 a$ and Apobec $2 \mathrm{~b}$ together, but not each individually, we observed a signif- icant decrease $(40 \%)$ in the injurydependent induction of asclla (Fig. 9B). These results suggested that Apobec $2 \mathrm{a}$ and Apobec $2 \mathrm{~b}$ contribute to asclla expression during optic nerve regeneration.

\section{Ascl1a, Apobec2a, and Apobec2b regulate axonal growth during optic nerve regeneration}

To investigate whether Asclla, Apboec2a, and Apobec $2 b$ are necessary for optic nerve regeneration, we combined in vivo morpholino-mediated retinal ganglion cell protein knockdown with retinal explants to assay ganglion cell axon regeneration (Veldman et al., 2010). For these experiments Gelfoam impregnated with apobec $2 a$, apobec $2 b$, ascl1 $a$, or control morpholino was applied to the lesioned optic nerve stump overnight. Four days later the retinas were harvested, diced and cultured as explants for $4 \mathrm{~d}$, after which retinal ganglion cell axonal growth was quantified as previously described (Veldman et al., 2010). Retinal explants prepared from control morpholino-treated retinas displayed robust axonal outgrowth, while knockdown of Ascl1a, Apobec2a or Apobec2b caused a significant suppression of optic axon regrowth (Fig. 9C,D). Therefore, similar to retina regeneration, Asclla, Apobec2a and Apobec $2 \mathrm{~b}$ also regulate optic axon regeneration.

\section{Discussion}

DNA demethylation is a key event in the reprogramming of fully differentiated somatic cells to acquire pluripotency (Simonsson and Gurdon, 2004; Mikkelsen et al., 2008; Bhutani et al., 2010; Jullien et al., 2011). Similarly, we hypothesize that following retina injury DNA demethylation underlies the reprogramming of Müller glia to acquire characteristics of a multipotent retinal progenitor. Many proteins have been implicated in the process of DNA demethylation including: Apobec proteins, Gadd45 proteins, MBD4, TDG, and TET proteins (see Introduction). Recent work suggests that these factors participate in a multistep process to carry out DNA demethylation (Guo et al., 2011; He et al., 2011). Importantly, Apobec proteins, Gadd45 proteins and DNA glycosylases have been implicated in DNA demethylation during zebrafish development (Rai et al., 2008).

To begin investigating whether these components participate in retina regeneration we measured their expression levels in uninjured and injured retinas. Although many of these genes showed constitutive expression, some demonstrated injurydependent induction. Of particular note, we report that apobec $2 a$ and $a p o b e c 2 b$ are induced in reprogramming Müller glia during retina regeneration and that $a p o b e c 2 b$ is induced in damaged 
ganglion cells after injury. In Müller glia, the increased expression of apobec $2 b$ is dependent on an early increase of Asclla (Fausett et al., 2008), but is independent of Lin28 (Ramachandran et al., 2010b). Knockdown of Apobec2b, like knockdown of Asclla and Lin28, significantly reduces the ability of Müller glia to respond to injury by dedifferentiating and proliferating. Thus, apobec $2 b$ represents an independent signaling pathway stemming from Asclla that is important for zebrafish retina regeneration. When the levels of Apobec2a were perturbed by morpholino knockdown, retina regeneration was also reduced. This suggests that Apobec2a and Apobec $2 \mathrm{~b}$ act in a nonredundant fashion. The crystal structure of human APOBEC2 indicates that it functions as a dimer or tetramer (Prochnow et al., 2007), so it is possible that zebrafish Müller glia reprogramming requires the oligomerization of Apobec2a and Apobec2b. When the levels of Apobec2a and/or Apobec $2 \mathrm{~b}$ were knocked down by antisense morpholino, the levels of asclla also decreased. This could explain why a similar knockdown of asclla and its target genes was seen after knockdown of Apobec2a and Apobec2b individually or in combination. We hypothesize that an early increase of Asclla is required for the induced expression of apobec $2 b$ and that Apobec2a and Apobec $2 \mathrm{~b}$ then function through oligomerization to actively demethylate gene promoters through a multistep reaction. One such promoter could be that of asclla. But, it is equally likely that Apobec2a and Apobec2b are acting on ascl1 $\mathrm{a}$ indirectly, acting to demethylate the promoters of other unknown genes that then feedback and activate asclla.

The expression of apobec $2 b$ and asclla (to a small extent) is also regulated during optic nerve regeneration, but unlike retina regeneration, knockdown of Asclla during optic nerve regeneration had no impact on the expression of apobec $2 b$. The induction of apobec $2 b$ in injured retinal ganglion cells likely explains why knockdown of Asclla during retina regeneration only results in a $\sim 77 \%$ reduction in the levels of apobec $2 b$ at $2 \mathrm{dpi}$, the residual increase of $a p o b e c 2 b$ being attributed to the injured ganglion cells. Although the mechanisms mediating injury-dependent $a p o b e c 2 b$ induction differ during retina and optic nerve regeneration, both involve Asclla, Apobec2a and Apobec2b expression and show regulation of asclla expression by Apobec2a and Apobec2b.

\section{The role of zebrafish Apobec2a and Apobec2b during regeneration}

That apobec $2 a$ and $a p o b e c 2 b$ were regulated during regeneration was somewhat surprising because previous work had largely localized Apobec2 to muscle tissue (Liao et al., 1999; Etard et al., 2010). The exact role that these proteins may play during retina regeneration remains unknown. Apobec proteins have traditionally been associated with cytidine deamination and editing of DNA and/or RNA (Conticello, 2008; Prochnow et al., 2009; Blanc and Davidson, 2010). However, unlike many mammalian APOBEC proteins with an assigned function, APOBEC2 remains an enigma with no clear mechanism of action and relatively few functions assigned. Human APOBEC2 appears to play a role in muscle development and may contribute to its adaptability (Etard et al., 2010; Sato et al., 2010). In Xenopus, Apobec2 has been reported to regulate left-right axis specification (Vonica et al., 2011), and in developing zebrafish Apobec $2 \mathrm{~b}$ stimulates DNA demethylation (Rai et al., 2008).

Early in vitro studies suggested that APOBEC2 had cytosine deaminase activity (Liao et al., 1999; Anant et al., 2001), but later studies refuted those findings (Mikl et al., 2005). APOBEC2 structural data demonstrate its potential to bind polynucleotides
(Prochnow et al., 2007; Bransteitter et al., 2009), but no studies have confirmed this binding. When considering the highly conserved amino acids in the Apobec family, Apobec2 would appear to be a fully functional deaminase. Importantly, transfection of cultured HEK293 cells with human APOBEC2 and TET1 stimulated DNA demethylation while overexpression of each individually did not (Guo et al., 2011). Likewise, overexpression of Aobec $2 \mathrm{~b}$ and hMBD4 during zebrafish development stimulated global DNA demethylation, but overexpression of each individually had no effect (Rai et al., 2008). Whether a similar scenario acts during retina regeneration or whether Apobec2a and Apobec2b function to modify RNA is unknown; nonetheless our data indicates that many of the components controlling DNA demethylation are induced following retina injury.

\section{Cellular reprogramming during regeneration}

Cellular reprogramming of Müller glia during retina regeneration and retinal ganglion cells during optic nerve regeneration likely has similarities and differences. Retina regeneration requires extensive Müller glia reprogramming, resulting in their dedifferentiation into a multipotent progenitor capable of regenerating all major retinal cell types (Fausett and Goldman, 2006; Raymond et al., 2006; Fimbel et al., 2007; Ramachandran et al., 2010a). Optic nerve regeneration differs from retina regeneration in that only one cell type is involved, and it occurs in the absence of proliferation. Yet, the ganglion cells during optic nerve regeneration likely require a high degree of reprogramming to reach an early developmental state allowing for correct axonal growth, path finding and synapse formation. These differences may contribute to the variation in amount of Apobec2a and Apobec $2 \mathrm{~b}$ present and their regulation.

This study establishes Apobec2a and Apobec $2 \mathrm{~b}$ as important components for retina and optic nerve regeneration. Whether Apobec2a and Apobec2b participate in active DNA demethylation during retina and optic nerve regeneration remains to be determined. To make this connection, two routes are possible. First, one could identify targets of Apobec2a or Apobec2b and characterize their methylation levels. This approach is limited because of the difficulty distinguishing between a direct and an indirect target. Alternatively, one could identify the regions of DNA undergoing DNA demethylation during retina regeneration, and determine whether Apobec proteins are required for their demethylation. Until one of these approaches is taken, the void existing between these proteins and DNA demethylation will remain. Further studies will attempt to close this gap using zebrafish retina regeneration as a model system.

\section{References}

Anant S, Mukhopadhyay D, Sankaranand V, Kennedy S, Henderson JO, Davidson NO (2001) ARCD-1, an apobec-1-related cytidine deaminase, exerts a dominant negative effect on C to U RNA editing. Am J Physiol Cell Physiol 281:C1904-C1916.

Bernardos RL, Barthel LK, Meyers JR, Raymond PA (2007) Late-stage neuronal progenitors in the retina are radial Muller glia that function as retinal stem cells. J Neurosci 27:7028-7040.

Bhutani N, Brady JJ, Damian M, Sacco A, Corbel SY, Blau HM (2010) Reprogramming towards pluripotency requires AID-dependent DNA demethylation. Nature 463:1042-1047.

Blanc V, Davidson NO (2010) APOBEC-1-mediated RNA editing. Wiley Interdiscip Rev Syst Biol Med 2:594-602.

Bransteitter R, Prochnow C, Chen XS (2009) The current structural and functional understanding of APOBEC deaminases. Cell Mol Life Sci 66:3137-3147.

Conticello SG (2008) The AID/APOBEC family of nucleic acid mutators. Genome Res 9:229. 
Cortellino S, Xu J, Sannai M, Moore R, Caretti E, Cigliano A, Le Coz M, Devarajan K, Wessels A, Soprano D, Abramowitz LK, Bartolomei MS, Rambow F, Bassi MR, Bruno T, Fanciulli M, Renner C, Klein-Szanto AJ, Matsumoto Y, Kobi D, et al. (2011) Thymine DNA glycosylase is essential for active DNA demethylation by linked deamination-base excision repair. Cell 146:67-79.

Daroczi B, Kari G, Ren Q, Dicker AP, Rodeck U (2009) Nuclear factor kap$\mathrm{paB}$ inhibitors alleviate and the proteasome inhibitor PS-341 exacerbates radiation toxicity in zebrafish embryos. Mol Cancer Ther 8:2625-2634.

Etard C, Roostalu U, Strähle U (2010) Lack of Apobec2-related proteins causes a dystrophic muscle phenotype in zebrafish embryos. J Cell Biol 189:527-539.

Fausett BV, Goldman D (2006) A role for alphal tubulin-expressing Muller glia in regeneration of the injured zebrafish retina. J Neurosci 26:6303-6313.

Fausett BV, Gumerson JD, Goldman D (2008) The proneural basic helixloop-helix gene asclla is required for retina regeneration. J Neurosci 28:1109-1117.

Fimbel SM, Montgomery JE, Burket CT, Hyde DR (2007) Regeneration of inner retinal neurons after intravitreal injection of ouabain in zebrafish. J Neurosci 27:1712-1724.

Guo JU, Su Y, Zhong C, Ming GL, Song H (2011) Hydroxylation of 5 -methylcytosine by TET1 promotes active DNA demethylation in the adult brain. Cell 145:423-434.

He YF, Li BZ, Li Z, Liu P, Wang Y, Tang Q, Ding J, Jia Y, Chen Z, Li L, Sun Y, Li X, Dai Q, Song CX, Zhang K, He C, Xu GL (2011) Tet-mediated formation of 5-carboxylcytosine and its excision by TDG in mammalian DNA. Science 333:1303-1307.

Herman JG, Baylin SB (2003) Gene silencing in cancer in association with promoter hypermethylation. N Engl J Med 349:2042-2054.

Ito S, D'Alessio AC, Taranova OV, Hong K, Sowers LC, Zhang Y (2010) Role of Tet proteins in $5 \mathrm{mC}$ to $5 \mathrm{hmC}$ conversion, ES-cell self-renewal and inner cell mass specification. Nature 466:1129-1133.

Jullien J, Pasque V, Halley-Stott RP, Miyamoto K, Gurdon JB (2011) Mechanisms of nuclear reprogramming by eggs and oocytes: a deterministic process? Nat Rev Mol Cell Biol 12:453-459.

Liao W, Hong SH, Chan BH, Rudolph FB, Clark SC, Chan L (1999) APOBEC-2, a cardiac- and skeletal muscle-specific member of the cytidine deaminase supergene family. Biochem Biophys Res Commun 260:398-404.

Ma DK, Jang MH, Guo JU, Kitabatake Y, Chang ML, Pow-Anpongkul N, Flavell RA, Lu B, Ming GL, Song H (2009a) Neuronal activity-induced Gadd45b promotes epigenetic DNA demethylation and adult neurogenesis. Science 323:1074-1077.

Ma DK, Guo JU, Ming GL, Song H (2009b) DNA excision repair proteins and Gadd45 as molecular players for active DNA demethylation. Cell Cycle 8:1526-1531.

Matsumoto T, Marusawa H, Endo Y, Ueda Y, Matsumoto Y, Chiba T (2006) Expression of APOBEC2 is transcriptionally regulated by NF-kappaB in human hepatocytes. FEBS Lett 580:731-735.

Mikkelsen TS, Hanna J, Zhang X, Ku M, Wernig M, Schorderet P, Bernstein BE, Jaenisch R, Lander ES, Meissner A (2008) Dissecting direct reprogramming through integrative genomic analysis. Nature 454:49-55.

Mikl MC, Watt IN, Lu M, Reik W, Davies SL, Neuberger MS, Rada C (2005) Mice deficient in APOBEC2 and APOBEC3. Mol Cell Biol 25:7270-7277.

Mohr F, Döhner K, Buske C, Rawat VP (2011) TET genes: new players in DNA demethylation and important determinants for stemness. Exp Hematol 39:272-281.
Morgan HD, Dean W, Coker HA, Reik W, Petersen-Mahrt SK (2004) Activation-induced cytidine deaminase deaminates 5-methylcytosine in DNA and is expressed in pluripotent tissues: implications for epigenetic reprogramming. J Biol Chem 279:52353-52360.

Popp C, Dean W, Feng S, Cokus SJ, Andrews S, Pellegrini M, Jacobsen SE, Reik W (2010) Genome-wide erasure of DNA methylation in mouse primordial germ cells is affected by AID deficiency. Nature 463:1101-1105.

Prochnow C, Bransteitter R, Klein MG, Goodman MF, Chen XS (2007) The APOBEC-2 crystal structure and functional implications for the deaminase AID. Nature 445:447-451.

Prochnow C, Bransteitter R, Chen XS (2009) APOBEC deaminases-mutases with defensive roles for immunity. Sci China C Life Sci 52:893-902.

Rai K, Huggins IJ, James SR, Karpf AR, Jones DA, Cairns BR (2008) DNA demethylation in zebrafish involves the coupling of a deaminase, a glycosylase, and gadd45. Cell 135:1201-1212.

Rai K, Sarkar S, Broadbent TJ, Voas M, Grossmann KF, Nadauld LD, Dehghanizadeh S, Hagos FT, Li Y, Toth RK, Chidester S, Bahr TM, Johnson WE, Sklow B, Burt R, Cairns BR, Jones DA (2010) DNA demethylase activity maintains intestinal cells in an undifferentiated state following loss of APC. Cell 142:930-942.

Ramachandran R, Reifler A, Parent J, Goldman D (2010a) Conditional expression and lineage tracing of tubala expressing cells during zebrafish development and retina regeneration. J Comp Neurol 18:4196-4212.

Ramachandran R, Fausett BV, Goldman D (2010b) Asclla regulates Muller glia dedifferentiation and retinal regeneration through a Lin28-dependent, let-7 microRNA signalling pathway. Nat Cell Biol 12:1101-1107.

Raymond PA, Barthel LK, Bernardos RL, Perkowski JJ (2006) Molecular characterization of retinal stem cells and their niches in adult zebrafish. BMC Dev Biol 6:36.

Sato Y, Probst HC, Tatsumi R, Ikeuchi Y, Neuberger MS, Rada C (2010) Deficiency in APOBEC2 leads to a shift in muscle fiber-type, diminished body mass and myopathy. J Biol Chem 285:7111-7118.

Simonsson S, Gurdon J (2004) DNA demethylation is necessary for the epigenetic reprogramming of somatic cell nuclei. Nat Cell Biol 6:984-990.

Urasaki A, Morvan G, Kawakami K (2006) Functional dissection of the Tol2 transposable element identified the minimal cis-sequence and a highly repetitive sequence in the subterminal region essential for transposition. Genetics 174:639-649.

Veldman MB, Bemben MA, Thompson RC, Goldman D (2007) Gene expression analysis of zebrafish retinal ganglion cells during optic nerve regeneration identifies KLF6a and KLF7a as important regulators of axon regeneration. Dev Biol 312:596-612.

Veldman MB, Bemben MA, Goldman D (2010) Tubala gene expression is regulated by KLF6/7 and is necessary for CNS development and regeneration in zebrafish. Mol Cell Neurosci 43:370-383.

Vonica A, Rosa A, Arduini BL, Brivanlou AH (2011) APOBEC2, a selective inhibitor of TGFbeta signaling, regulates left-right axis specification during early embryogenesis. Dev Biol 350:13-23.

Wu SC, Zhang Y (2010) Active DNA demethylation: many roads lead to Rome. Nat Rev Mol Cell Biol 11:607-620.

Zhu B, Zheng Y, Angliker H, Schwarz S, Thiry S, Siegmann M, Jost JP (2000) 5-Methylcytosine DNA glycosylase activity is also present in the human MBD4 (G/T mismatch glycosylase) and in a related avian sequence. Nucleic Acids Res 28:4157-4165.

Zhu JK (2009) Active DNA demethylation mediated by DNA glycosylases. Annu Rev Genet 43:143-166. 